$8-2014$

\title{
Critical Influences That Encourage Adolescent Boys to Engage in Leisure Reading
}

Adam Wyse

Cedarville University

Follow this and additional works at: http://digitalcommons.cedarville.edu/education theses

Part of the Education Commons

\section{Recommended Citation}

Wyse, Adam, "Critical Influences That Encourage Adolescent Boys to Engage in Leisure Reading" (2014). Master of Education Research Theses. 71.

http://digitalcommons.cedarville.edu/education_theses/71 


\title{
CRITICAL INFLUENCES THAT ENCOURAGE ADOLESCENT BOYS TO ENGAGE IN LEISURE READING
}

\author{
A research proposal \\ submitted in partial fulfillment of the requirements of the degree \\ Masters of Education
}

by

Adam Wyse

B.A. English, Grove City College, 1996

2014

Cedarville University 


\begin{abstract}
This mixed-method study identifies influences on the literacy habits of adolescent boys. The study sought to answer the question: what factors influence adolescent boys to pursue or not pursue leisure reading? Leisure reading has been found to have a positive impact on academic success (Hughes-Hassell \& Rodge, 2007) and boys tend to lag behind in engaging it (Smith \& Wilhelm, 2004). A Likert scale survey was given to 137 students, boys and girls, from an uppermiddle class, private Christian school in the Midwest. Questions focused on why students do or do not read and what could encourage them to increase their leisure reading frequency. An open-ended question at the end of the survey provided qualitative data. Informed consent was obtained from all participants and no compensation was given.

Hundreds of studies have been conducted in recent decades on increasing adolescent literacy, specifically for boys, but no definitive cure-alls have been found. Each study seems to result in a different, sometimes conflicting answer depending on its sample and focus.

This study also did not find definitive, easy answers to getting adolescent boys to read for pleasure more often. It confirmed some results in published literature including gender preferences for genres and boys needing a reason to read such as inquiry questions. This study contradicted other established ideas such as boys responding positively to technology as a gateway to increasing reading, needing male role models to encourage them to read, perceiving reading as a feminine activity, or believing they were less competent readers than girls. However, the literature at large as well as the pertinent results of this study will be useful to local educators working with their unique student populations to increase adolescent male literacy.
\end{abstract}




\section{Table of Contents}

I. Introduction

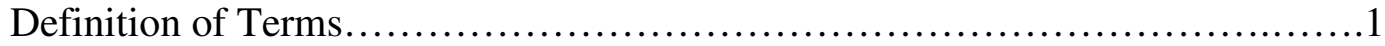

Statement of the Problem...................................................... 4

Scope of the Study and Delimitations........................................ 10

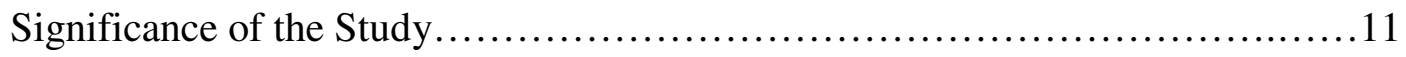

Methods of Procedure..................................................... 12

II. Literature Review

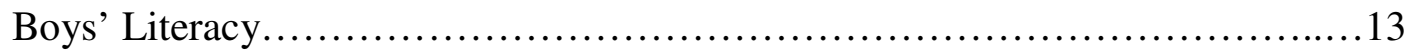

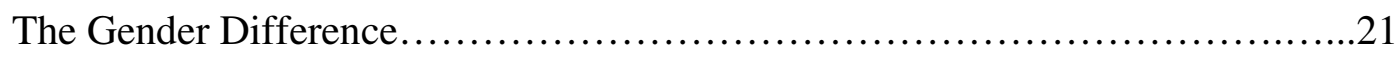

At-Risk Youth and Urban Fiction...............................................25

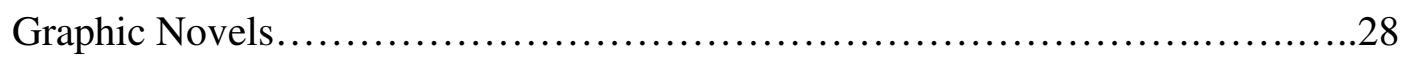

Urban Youth............................................................... 30

III. Methods

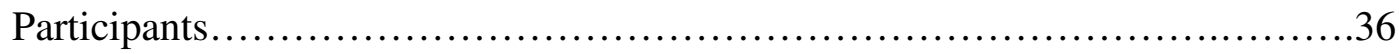

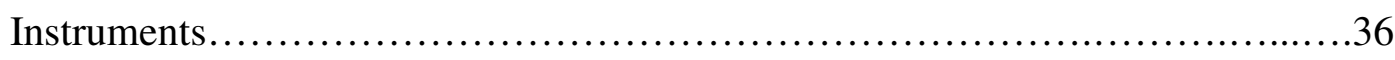

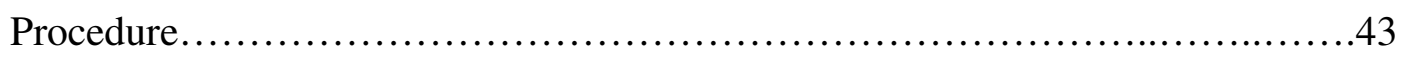

IV. Results

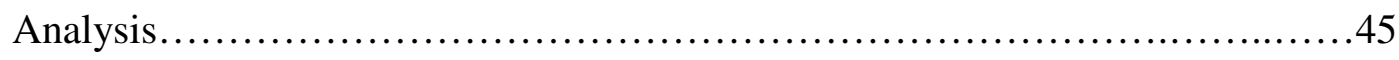

Data Results

Gender............................................................ 46

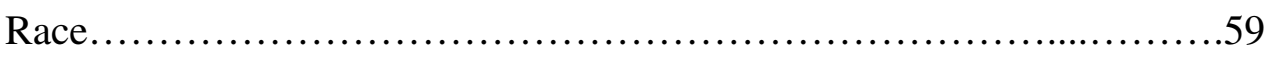

Open-ended Results.....................................................61

V. Conclusion

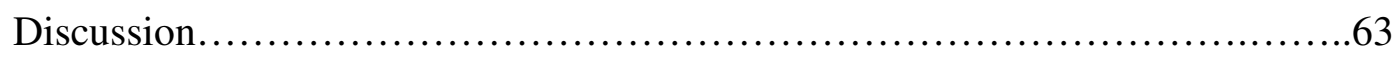

Suggestions for Further Study .................................................66

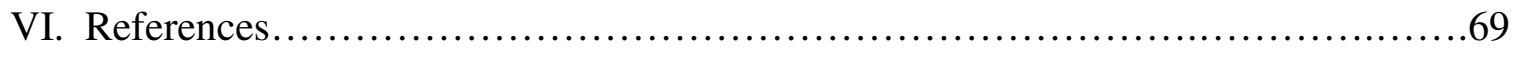

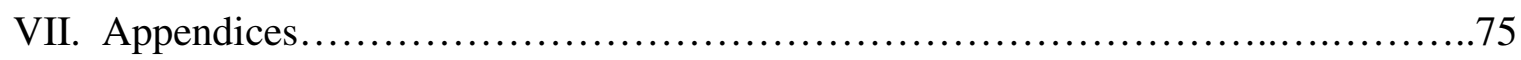




\section{Chapter one}

\section{Introduction}

Reading is to the mind what exercise is to the body. -Sir Richard Steele

Proficiency in reading is the strongest predictor of school success (Sokal, 2010), and leisure reading in particular has a strong correlation to academic achievement (Hughes-Hassell \& Rodge, 2007). A lack of leisure reading is particularly troubling for middle school adolescents, who are at a crucial time in enhancing literacy habits before the start of high school, when the amount and difficulty of the material increases and teacher assistance may actually decrease (Smith \& Wilhelm, 2004; Wheldall \& Watkins, 2004).

Males in this age bracket seem to be at the highest risk for disengaging from literature as many studies have found a persistent gender gap throughout schooling (Canadian Council on Learning, 2009; Sadowski, 2010; Sokal, 2010). Dropout rates are higher for males and high literacy is found to reduce those (Boone, Rawson, \& Vance, 2010; Bowen, Hopson, Rose, \& Glennie, 2012; Guerra, 2012). Given that leisure reading produces academic gains, it seems important to find out why males drop reading books around the middle school years and how educators can get them to re-engage with the beneficial pursuit of leisure reading.

\section{Definition of Terms}

Academic relevancy — the extent to which capabilities required for the present activity are similar to those capabilities required for a future task, specifically when students experience their 
course content as relevant, personally meaningful, and connected to the real world (Crumpton \& Gregory, 2011).

Cultural capital—a mechanism used by society's affluent parents to socialize their children to develop cultural and educational competencies and successes (Harris \& Graves Jr., 2010).

Essential (or inquiry) questions - inquiries into broad themes of life with no set answers that a student must interpret through the action in stories. Examples include "If we can, should we?", "Can you buy your way to happiness?", and "What is beauty and/or beautiful?" (Fisher \& Frey, 2012)

Graphic novels - a format for works of fiction and nonfiction containing illustrations which provide visual clues to the meaning of the print and dialogue (Brozo, 2012; Moeller, 2011). Book-length stories published in comic-book style with artwork, complex characters, welldeveloped story lines, and literary devices like foreshadowing and allusion (Hughes-Hassell \& Rodge, 2007).

Leisure reading - the reading of any text over which the reader has selection control and is done outside of school or reading that students choose to do on their own as opposed to reading that is assigned to them (Hughes-Hassell \& Rodge, 2007).

Literacy--the ability to use printed and written information to function in society, to achieve one's goals, and to develop one's knowledge and potential (NAAL, 2012). 
Motivation- a person's willingness to exert physical or mental effort in order to complete a goal or set aim (psychologydictionary.org).

Old timers' books/Classic novels - novels of literary significance that have withstood the test of time and remained popular years after their publication. Generally, they contain wide, global themes that can be applied to any time period. A classic usually contains some kind of widespread, universal appeal that results in it being read and embraced by a wide audience of diverse people. Most widely-observed classic novels are at least several decades old and still widely read (www.wisegeek.com).

Scaffolding — the process through which a mentor supports a child toward success (Sokal, 2010).

Self-efficacy — the belief in one's capabilities to organize and execute the courses of action required to manage prospective situations (Bandura, 1994).

Socio-economic status (SES) — the social standing or class of an individual or group. It is often measured as a combination of education, income and occupation. Examinations of socioeconomic status often reveal inequities in access to resources, plus issues related to privilege, power and control (www.apa.org).

Urban fiction/street lit— works set in urban America dealing with drugs, violence, poverty, crime, incarceration, and sex, involving African American or Latino characters (Guerra, 2012).

Young adult (YA) literature— books written specifically for a teenage audience (@ 12-18). The books usually have a young protagonist and present that young person dealing with issues 
that all other young people face (belonging, falling in love, deciding what to do in the future) or issues that young people are afraid they may have to face (violence, drugs, alcoholism, being along, death of a loved one, pregnancy, or divorce) (Koren, September 13, 2008).

Zone of proximal development (ZPD) — the area that exists between the actual developmental level of a child and the level at which children can successfully complete tasks with assistance (Vygotsky, 1978).

\section{Statement of the Problem}

Research question:

1. What factors influence adolescent boys to pursue or not pursue leisure reading?

The circulation of this researcher's school library drops dramatically from $6^{\text {th }}$ through $8^{\text {th }}$ grade. Why don't students continue to read in the adolescent years? Specifically, what do boys need to spur them on in reading?

Some studies found gender differences in the approach to reading to be the primary issue (Canadian Council on Learning, 2009). Further studies pointed out that reading may be perceived as a feminine activity (Canadian Council on Learning, 2009; Moeller, 2011; Watson, Kehler, \& Martino, 2010; Werderich, 2010). Other studies have found competence and selfefficacy were the most important motivators for boys to read (McDowell, Sweeney, \& Ziolkowski, 2011; Smith \& Wilhelm, 2004). Finally, other research showed that boys didn't reject reading universally, just in the form of school assignments because of the way it was 
presented (Fisher \& Frey, 2012; Fredrick, 2006; Kirkland, 2011; Smith \& Wilhelm, 2004). So the problem is, no one really knows what the problem is in terms of a consistent obstacle to boys reading for pleasure. Likely, it's a combination of these factors that also includes home and school environment.

To identify influences on boys' literacy, the survey in this study will address questions of gender differences (Canadian Council on Learning, 2009; Clark, 2010; Fredrick, 2006; Guerra, 2012; Kirkland, 2011; Moeller, 2011; Smith \& Wilhelm, 2004; Werderich, 2010), boys' feelings of competence in reading (McDowell et al., 2011; Smith \& Wilhelm, 2004), and the role of teacher support and modeling (Boone et al., 2010; Bowen et al., 2012; Fisher \& Frey, 2012; Fredrick, 2006; Gillespie, 2010; Werderich, 2010).

The emphasis on gender differences as related to reading achievement comes and goes with various studies, decades, and the latest crisis in schools. Gender differences include not only examining the hard-wiring of boys for literacy but also the impact of having male or female teachers as well as whether reading is perceived as a masculine or feminine activity (Canadian Council on Learning, 2009; Moeller, 2011; Sokal, 2010). The Canadian Council on Learning (2009) found that throughout the school years, boys and girls essentially came out even in math and science, but a significant reading gap remained the whole time. One explanation is that the genres boys prefer aren't offered in most classrooms (Canadian Council on Learning, 2009; Husband, 2012). Boys end up having fewer reading experiences, which, just like skipping practices for a sport, puts them behind (Husband, 2012). In addition, the Canadian Council (2009) study found that reading was perceived more as a girls' pastime, making boys less likely to engage. Although some have proposed having more male teachers to encourage boys' literacy, several studies found no evidence that having male teachers influenced boys to read 
more (Canadian Council on Learning, 2009; Sokal, 2010; Werderich, 2010) while others said it's crucial (Canadian Council on Learning, 2009; Henry, Lagos, \& Berndt, 2012). However, in its list of methods to engage boys in reading, the council did suggest boys need male reading role models (Canadian Council on Learning, 2009).

In his own classroom, this researcher has observed a positive connection with boys in regards to reading. Currently, in the K-12 grades, only two Language Arts teachers are male. This researcher has heard negative comments about the themes of some books chosen by students' female teachers, particularly below grade 8 in the young adult literature genre. Within his first few years of teaching, this researcher began using The Hobbit by J.R.R. Tolkien as a resource. Despite warnings against using the whole-class novel (Allyn, 2011), parents of boys soon commented how their child normally didn't like to read anything and now wanted the entire Lord of the Rings trilogy for Christmas. Boys appreciated the fantasy genre and also later responded positively to a unit on Norse mythology with its darker themes and action.

Data from Smith and Wilhelm (2004), on the other hand, showed that boys did not see reading as a feminine pastime. The issue with the participants for that study was competence and self-efficacy. Most of those boys actually wished they were better readers, but felt they didn't have the skill and believed it would take too long to develop (Smith \& Wilhelm, 2004). However, this mainly applied to school texts, which the students found too difficult and irrelevant to their time and experience (Smith \& Wilhelm, 2004). Outside school, the boys would tackle literature of any complexity if it was a topic of interest to them (Smith \& Wilhelm, 2004).

The research of Watson, Kehler, and Martino (2010) also found that feminization of school was not the problem and felt that the usual solutions like having male teachers and using 
more "boy-friendly strategies and resources", was oversimplifying the problem (Watson et al., 2010). They believe that the "boy problem" has been packaged so the general public can understand it and schools can write policy about it (Watson et al., 2010), but what is really needed, they argue, is a change in the whole societal construct of masculinity (Watson et al., 2010).

Tim Fredrick, a $9^{\text {th }}$ grade English teacher at Thurgood Marshall Academy in Harlem, New York, described his experience as a dedicated reader moving through his schooling years. Because he inherently loved reading, the gender of the teacher had no impact. He constantly sought books for himself regardless of the classroom environment. Mr. Fredrick commented, however, that while his history is not unique, it is uncommon with boys (Fredrick, 2006). Now in his own classroom, even though he believed both genders logically understand the importance of literacy and want essentially the same fulfilling experience from reading, he found he must work harder to engage boys who do not share the same inherent love of books.

We cannot ignore the fact that most ELA (English Language Arts) teachers are female and those of us who are male are those men who succeeded in classrooms dominated by female literacy. The problem begins to feed on itself-those who become ELA teachers are those who succeed in female literacy-dominated classrooms and they model their classroom after the classroom of their own experience. Adolescent males who are most engaged by male literacy-dominated texts and activities are being left out of these classrooms. (Fredrick, 2006)

This researcher has a similar background. Intrinsically motivated to read, he devoured books given by teachers of either gender and committed to the reading experience 
whether or not the book was high interest. There was always something to gain by reading a book. Coming to the classroom, the researcher struggled with why students, especially boys, would not simply read for the experience and find value in any book. This has led the researcher to be particularly interested in finding genres that appeal to boys as well as using essential questions (Fisher \& Frey, 2012) to generate a need to read.

Whatever the problems associated with reading for males, the difficulties seem greater and the consequences worse for urban teens (Boone et al., 2010; Bowen et al., 2012; HughesHassell \& Rodge, 2007; Husband, 2012). While white male dropouts may still enter the workforce in labor jobs, black teen dropouts tend to move toward juvenile delinquency and petty crime (Boone et al., 2010). And while motivating factors for reading may be the same for adolescent males of all strata, urban teens have the additional obstacle of socio-economic status (SES) factors, mainly poverty, or the attitude that being smart is "acting white" (Tatum \& Muhammad, 2012). Acting white is "set of social interactions in which minority adolescents who get good grades in school enjoy less social popularity than white students who do well academically" (Fryer, 2006) In certain cases, minorities who succeed in school suffer a social cost to do so through negative peer pressure. Therefore, striving to increase their literacy may be too high a price to pay. To combat low urban teen literacy, Boone et al. (2004) suggest that teachers and librarians first examine their own prejudices and not treat urban teens as if they can't learn or can't be successful at reading (Boone et al., 2010; Tatum, 2003). Guerra (2004) then offers the debate to use urban fiction or street lit to reach incarcerated youth.

Urban fiction deals with the dark and gritty themes of the streets. On one hand, this may be the first step to getting adolescent males to read since they can identify with the themes and characters. On the other hand, these books may simply validate and perpetuate the lifestyle that 
led these teens to prison (Guerra, 2012). In either case, her analysis of research shows that literacy is a powerful deterrent to incarceration as well as a factor in inmates not returning to prison once released (Guerra, 2012).

Wheldall and Watkins (2004), however, found the idea that low literacy was linked to juvenile delinquency had become an accepted idea without a lot of evidence. They found that it could be one factor, but the majority of the detainees they studied had functioning literacy levels, although they admit the scale they used places "functioning" at the equivalent of 10.5 years. Still, they believe those who propose increasing literacy to empty the prisons are oversimplifying the problem (Wheldall \& Watkins, 2004).

Finally, Hughes-Hassel (2007) reiterated the positive links between leisure reading and academic achievement. She also found a high percentage of urban teens reporting that they engage in leisure reading, which caused her to wonder why reading scores then remained low in urban schools. Her primary theories were that students perhaps were not reading as much as reported, the greatest preference for leisure reading was magazines, which may not translate to significant gains in heavier school reading, and schools may not be assessing in ways that show students' reading strengths because of the difference in what students and teachers regard as quality literature (Hughes-Hassell \& Rodge, 2007). She then outlined several strategies which are detailed in Chapter Two for enhancing urban teen leisure reading.

Bowen et al. (2010) identified the middle school years as a strong predictor of dropout rates. He identified parental support and expectations and more importantly, students' perceptions of parental expectations, as key elements in school success. Strong parental involvement could do a great deal against negative SES factors such as poverty (Bowen et al., 2012). Lutz (1986) cited additional research showing a link between parents modeling reading at 
home and students reading at home with higher reading achievement in school. Kloosterman (2011) also found that parental reading socialization in the early years had a positive impact on children's reading achievement. Calling it "transmission of cultural capital”, Harris and Graves (2010) found parental involvement a key component of academic success. Coley, Lewin-Bizan, and Carrano (2011) showed evidence that early, warm, responsive fathering in low-income families had a positive impact on children's cognitive skills that lasted through middle childhood.

To confirm the various theories on what influences boys' literacy, the survey for this study will ask questions about gender differences (Canadian Council on Learning, 2009; Clark, 2010; Gillespie, 2010; Moeller, 2011; Werderich, 2010), African American motivation for reading and cultural capital (Guerra, 2012; Harris \& Graves Jr., 2010; Hughes-Hassell \& Rodge, 2007; Husband, 2012; Kirkland, 2011), feelings of competence and self-efficacy (Boone et al., 2010; McDowell et al., 2011; Smith \& Wilhelm, 2004), and parental involvement (Harris \& Graves Jr., 2010; Hughes-Hassell \& Rodge, 2007).

\section{Scope of the Study and Delimitations}

The researcher delivered a survey to the $7^{\text {th }}$ and $8^{\text {th }}$ grade students of a private Christian school in the Midwest. This particular school has an upper-middle class population with a total enrollment K-12 of 950 . The $7^{\text {th }}$ and $8^{\text {th }}$ grades have 151 students, 14 of whom attend on EdChoice, the state voucher program, and 25 others receive financial assistance. Informed consent was obtained from 141 of the 151 students. Due to several absences, 137 students completed the online survey. Students took the survey using laptop computers from a laptop cart during their Language Arts class period on either Wednesday, Thursday, or Friday in late May 
2014. Class periods began at 8:45 A.M., 10:13 A.M, 10:58 A.M., 12:24 P.M., and 2:35 P.M. Students averaged ten minutes to complete the survey. Although the researcher was mainly interested in collecting data on male reading habits and influences, all the students took the survey in order to be able to find significant differences between genders and for anecdotal information on female reading habits and influences.

The adolescent population of this middle school was 151 and relatively homogeneous; therefore the sample size $(N=137)$ was sufficient with balanced gender subpopulations (Males=76, Females=61) (Johnson \& Christensen, 2008a).

Delimitations included not controlling for marital status or income level.

\section{Significance of the Study}

High literacy rates and engaging in leisure reading in particular are shown to greatly impact academic achievement and reduce problem behavior and dropout rates (Guerra, 2012; Hughes-Hassell \& Rodge, 2007). If there is a window of schooling where boys tend to disengage from reading, it's important to know why. Teachers and librarians can work with parents to shore up this critical time so boys continue to read to promote their future success. If the study can determine which factors influence boys the most, educators and parents can tap into those to encourage reading.

In fact, the window may be narrower than supposed. Several studies have shown that by grade 2, gender gaps begin to open in reading and boys begin the spiraling process of falling behind in literacy (Canadian Council on Learning, 2009).

Although studies like this have been done before, this researcher believes it's appropriate to continue for several reasons. First, studies need to be updated. Maybe a landmark study from 
1974 is the definitive word on a subject, but rarely. Circumstances change and even if the data results do end up being similar, it's appropriate to check. Second, because this is an area where the researcher can have a personal impact with students, he wants to know firsthand with what he's dealing. This researcher can read others' results, but wants to internalize this issue to be confident in this field of knowledge. Finally, as stated previously, every study seemed to result in a different conclusion about the main influence on male adolescent literacy, so this researcher would like to find his own results based on the survey developed.

\section{Methods of Procedure}

An online survey (www.surveymonkey.com) with thirty-four questions using a Likert scale plus one open-ended question at the end was the vehicle for collecting data. The survey was given to all enrolled $7^{\text {th }}$ and $8^{\text {th }}$ graders from whom consent was obtained. The researcher then reviewed answers to the open-ended question, as well. Students used individual laptop computers to take the survey and completed it within one class period. Data was coded and run through statistical software to see if any significant differences were found among various interactions. 


\section{Chapter two}

\section{Literature Review}

Boys’ Literacy

Reading proficiency is one of the strongest predictors of school success, insulates against academic failure, and sets a more positive life trajectory (Henry et al., 2012; Sells, 2009; Sokal, 2010). In particular, leisure reading is correlated with school success including greater vocabulary, reading comprehension, verbal fluency, and content knowledge (Hughes-Hassell \& Rodge, 2007; Sells, 2009). Boys, however, lag in reading and pose a particular challenge to engaging in literacy (Banks, 2011; Canadian Council on Learning, 2009; Clark, 2010; Fredrick, 2006; Husband, 2012; Sadowski, 2010; Smith \& Wilhelm, 2004; Sokal, 2010; Tatum, 2006;

Werderich, 2010). Decades of research and hundreds of studies have identified many factors and proposed many solutions but the dilemma hasn't changed.

"I don't think that any one strategy will really 'crack' the problem of boys' literacy and reading completely" (Banks, 2011).

However, taking all the literature together, this researcher found that several components of a possible solution appeared consistently.

The critical factors in fostering boys' literacy are motivation or interest, choice, competency or self-efficacy, and the role of the teacher (Elish-Piper \& Tatum, 2006; Fisher \& Frey, 2012; Fredrick, 2006; Kirkland, 2011; Smith \& Wilhelm, 2004). These factors are discussed first, then other facets of adolescent male literacy are covered.

What seems to be the key to male literacy is motivation or interest (Bozack, 2011; Canadian Council on Learning, 2009; Elish-Piper \& Tatum, 2006; Fisher \& Frey, 2012; Graham, Tisher, Ainley, \& Kennedy, 2008; Sells, 2009; Smith \& Wilhelm, 2004). Boys need a reason to 
read (Elish-Piper \& Tatum, 2006). There must be purpose in it. Primarily this involves seeing themselves in the text somehow, meaning they identify with the characters or the setting, having questions they want to find answers for, or finding the book relevant to their lives in some way (Crumpton \& Gregory, 2011; Fisher \& Frey, 2012; Fredrick, 2006; Kirkland, 2011; Moeller, 2011). Seeing themselves in the text was more important for African Americans and will be addressed later in this review. Inquiry questions are covered in a later section on gender.

Relevancy again is the need for students to connect what they are learning in the classroom to what they will need to do in the future. When students find schoolwork, in this case reading, relevant to their lives, their engagement increases. Greater engagement leads to greater motivation which some have found to be a predictor of high academic achievement. Particularly for low-achieving students, greater engagement protects against retention and dropping out (Crumpton \& Gregory, 2011).

Interestingly, the published study linked increased relevancy to greater classroom engagement, but did not significantly find then that greater engagement lead to higher academic achievement (Crumpton \& Gregory, 2011). This contradicted the findings of other studies. However, this present study is mainly concerned with leisure reading, so if relevancy can lead simply to greater engagement with a student's independent reading outside the classroom, that would be a positive outcome.

In fact, Fredrick (2006) found that students were doing a lot of reading and writing in and out of his classroom, just not on the topics he had assigned. When students were bored, they would read and write on subjects of their own interest that meant more to them. They wanted immediate application. Even though Fredrick told his students broadly that an education would help them their entire lives, they still wanted that education to help them at the present moment. 
Fredrick then allowed the students greater choice in their classroom text selection and instituted student reflections and surveys and literature circles. This fostered student discussions centered on how the characters in books were much like themselves and the students could make immediate connections to their lives (Fredrick, 2006).

In his own classroom, this researcher has naturally tried to emphasize that the act of reading itself is relevant to students' future pursuits as nearly any job requires a degree of literacy. The researcher has not necessarily tried to make the difficult case that a particular book is relevant, especially if it's in the fantasy genre or a classic novel. However, he continually stresses that human nature hasn't changed and the ideas, actions, and consequences of characters or groups in books can be seen in the modern world, and the lessons of the book can be applied to a student's life.

To increase boys' leisure reading, the survey for this study will ask questions about identifying with characters and inquiry as motivations to read (Fisher \& Frey, 2012; Kirkland, 2011; Moeller, 2011). Nearly all students read voluntarily outside of school in areas of their interests or inquiry, e.g., fashion or hobby magazines (Elish-Piper \& Tatum, 2006), which is the beginning of choice.

The ability of choice in reading is a powerful motivator (Allyn, 2011; Boone et al., 2010; Elish-Piper \& Tatum, 2006; Fisher \& Frey, 2012; Guerra, 2012; Werderich, 2010). From the average public school student to at-risk and incarcerated youth who failed with assigned books and just want to read what interests them, choice of text is near the top of the list in generating interest in reading (Fisher \& Frey, 2012; Guerra, 2012). This isn't defined as a free-for-all, however. In fact, students independently read more books after guidance from their teachers which included teacher modeling of how to think about a book's themes, teacher read-alouds of 
varied and high-interest texts, using essential questions of inquiry to give students something to look for, and follow-up activities such as blogs and dialogue journals (Fisher \& Frey, 2012; Werderich, 2010; Witte, 2007).

Sokal (2010), however, found an important distinction to the advantage of choice. She discovered that having choice positively affected students' emotional response to a text but didn't necessarily increase the cognitive results (Sokal, 2010). If a teacher offers a "choice" of five books from a list the teacher created, but none of those books interest a student, there will be no greater learning (Fredrick, 2006; Sokal, 2010). Sokal (2010) also found that students who were given no choice performed better. In this case, however, reading tutors were directed to choose high interest books in the students' zone of proximal development (ZPD) and had weekly reading practice with those tutors employing scaffolding (Sokal, 2010). What she calls an exception to the benefit of choice, though, actually supports the literature that students choose better books after teacher support and scaffolding if choice is not defined as a free-for-all (Boone et al., 2010; Fisher \& Frey, 2012; Gillespie, 2010; Smith \& Wilhelm, 2004; Werderich, 2010). In this researcher's classroom, providing choice has yielded mixed results. Students are assigned three books to read independently during the year-fiction, nonfiction, and a biography. With a minimum page count, students are free to choose almost any book. However, this researcher has observed that this choice has not produced greater enthusiasm for reading. Students still regard the extra reading as a chore and wait until the last minute to rush through the books. On the other hand, a written report was also assigned during the year. With a very few caveats, students were free to choose their topic. This researcher received positive feedback from students on the ability to choose their subjects rather than being assigned a "boring" topic by the teacher. 
One study cautions against the "quick fixes" for boys including more male teachers, greater choice of text, and using more computer-based reading (Sokal, 2010). On the other hand, many studies have found choice to be a primary motivating factor (Boone et al., 2010; Bozack, 2011; Fisher \& Frey, 2012; Fredrick, 2006; Guerra, 2012; Hughes-Hassell, 2012). While this researcher agrees with avoiding "band-aid" solutions, you also have to go where the research takes you. Providing the type of literature boys like and allowing them to choose is a good start and will give them confidence to approach harder works (Fisher \& Frey, 2012).

"Failure in reading tops the list of esteem-busting events in the lives of boys" (Henry et al., 2012). Self-efficacy, or competence or self-esteem, are important components in boys wanting to read and develop literacy skills (McDowell et al., 2011; Richter, 2006; Smith \& Wilhelm, 2004). The psychologist Albert Bandura researched "ways that people's perceptions of their capabilities affect their courses of action" (Smith \& Wilhelm, 2004). This applies to many areas of life including literacy. Because boys fall behind girls in reading so early, they don't want to appear dumb in class and will often disengage from reading under the guise that it's uncool (Canadian Council on Learning, 2009; Scholes, 2010). However, boys recognize the value of reading and want to be good at it; they just want it right away and need immediate feedback to reinforce their progress (Fredrick, 2006; Smith \& Wilhelm, 2004). Boys didn't reject literacy altogether. They rejected it because of the presentation and school context (Fisher \& Frey, 2012; Kirkland, 2011; Smith \& Wilhelm, 2004). Either the books were too hard and they believed it would take too much effort to succeed, or they felt they weren't receiving the immediate feedback and support from the teacher (Kirkland, 2011; Werderich, 2010; Witte, 2007). Teachers should scaffold instruction to help these boys feel they can understand more difficult reading (Boone et al., 2010; Sokal, 2010). To increase boys' leisure reading, the survey 
for this study will ask questions related to competence in reading (Boone et al., 2010; McDowell et al., 2011; Smith \& Wilhelm, 2004).

However, McDowell (2011) asks if this is the chicken or the egg--“Does positive academic esteem help foster better reading skills or does better reading skills help develop positive academic esteem?" These factors likely work in tandem. One reason positive progress in this cycle could be disrupted is the gap that exists between students' perceptions of their own efforts and abilities and teachers' perceptions of the reading abilities of the students (Bozack, 2011). In other words, not only does each party operate on certain perceptions about themselves, but they also may misinterpret the other party's belief about them (Bozack, 2011). Teachers first need to communicate that they believe in the ability of all their students to gain ground in literacy (McDowell et al., 2011).

This researcher has not encountered the issue of self-efficacy to a great degree in his own classroom. There have been frequent discussions with parents and other teachers about poor readers taking longer to complete assignments and therefore they aren't excited about reading, but that has been the case for both boys and girls. The researcher has not discussed self-efficacy in depth with individual male students. The published literature has been enlightening in that area.

Although this present study seeks to promote independent leisure reading, research indicates a great deal of motivation starts in the classroom (Elish-Piper \& Tatum, 2006; Kirkland, 2011; Witte, 2007). "Getting boys to read is not simply a matter of locating texts with a male protagonist in an action-oriented setting or stocking libraries with graphic novels" (Fisher \& Frey, 2012). Enthusiastic teachers using engaging presentations and meaningful follow-up activities can ignite the love of books and inspire students to seek their own reading experiences 
(Banks, 2011; Elish-Piper \& Tatum, 2006; Hughes-Hassell \& Rodge, 2007; Werderich, 2010;

Witte, 2007). Initially, getting boys interested in reading is not a matter of simply turning them loose on the shelves and telling them to pick what they like (Fisher \& Frey, 2012). Young people sometimes don't know what to do with a book other than just read it (Fredrick, 2006). Students want to feel supported by their teachers (Bowen et al., 2012; Fisher \& Frey, 2012; Gillespie, 2010; Werderich, 2010). When teachers read aloud in class, model their thinking and writing on a book's themes, and, using meaningful questions, provide a forum for student discussion in the form of dialogue journals or blogs, students' interest in the book increases dramatically and they have more tools to engage books independently (Elish-Piper \& Tatum, 2006; Werderich, 2010; Witte, 2007). "The touchstone text that the teacher read was viewed as a platform for making connections to other pieces" (Fisher \& Frey, 2012).

In this researcher's classroom, modeling his own writing and thinking for assignments to show the students he wouldn't ask them to do anything he wouldn't do has received positive feedback including one under-the-breath comment that was overheard, "You're a good teacher." Later in this review is the idea of broadening the definition of what is acceptable reading to include almost anything that will get boys started (Allyn, 2011; Canadian Council on Learning, 2009; Sadowski, 2010). While that's a good start, Sadowski (2010) warns that ultimately that won't be enough because students need to be able to handle serious academic texts. The role of educators is to bridge that divide between what's fun and what's necessary by giving students skills and teaching them how to find the value in more difficult material (Fisher \& Frey, 2012; Smith \& Wilhelm, 2004). Teachers, however, aren't the only party to affect adolescent reading. 
Although parental involvement to encourage literacy is helpful to both boys and girls (Hughes-Hassell \& Rodge, 2007), it's worth mentioning since this study seeks ways educators and families can work together to help boys read. "Parental support and expectations are among the most important influences on students' behavior and academic performance, especially for students in the middle school years" (Bowen et al., 2012). Lutz (1986) found that students who read at home had higher achievement scores. Moreover, those students came from homes where family members modeled reading and supplied time and resources to foster the habit (Lutz, 1986). High parental expectations were found to be a predictor of success through the middle grades (Bowen et al., 2012).

A concept that was discussed in a study of African Americans but could apply to anyone was "cultural capital." Cultural capital is defined as "a mechanism used by society's affluent parents to socialize their children to develop cultural and educational competencies and successes" (Harris \& Graves Jr., 2010). In a broader sense, this means that through consistent parent-child discussions about school and life in general, the child absorbs the values and expectations of the family and culture (Harris \& Graves Jr., 2010). The particular study that introduced this concept focused on middle childhood (ages 6-12) (Harris \& Graves Jr., 2010). This present study is focused on the top end of that and higher. However, the Harris and Graves (2010) study found that the middle childhood years were the crucial time to establish the pattern of transmitting cultural capital. When children reached middle school, the influence of peers became greater, outside activities demanded more time, and students developed greater selfawareness and began to desire and assert more independence (Harris \& Graves Jr., 2010). The study found that the interaction between child and parent, specifically in the occurrence of narrative and explanatory talk while visiting places such as museums, libraries, and zoos, had a 
positive impact on reading achievement (Harris \& Graves Jr., 2010). To increase boys' literacy, the survey for this study will ask questions related to parent support and modeling (Bowen et al., 2012; Harris \& Graves Jr., 2010; Hughes-Hassell \& Rodge, 2007; Lutz, 1986).

Interestingly, two studies found that encouragement from other influential adults in students' lives did not produce the same gains as parent support (Bowen et al., 2012; Harris \& Graves Jr., 2010).

Finally, some studies encourage the use of technology, which is considered primarily a male domain, to foster literacy with boys (Sokal, 2010; Witte, 2007). Since some boys consider reading a feminine activity (Canadian Council on Learning, 2009; Moeller, 2011; Werderich, 2010), the idea is to present reading through a "masculine format" to offset the feminine perception (Sokal, 2010). It was found, however, that although technology produced better attitudes initially, the novelty wore off and some features such as links and animation in multimedia books actually distracted readers and increased fatigue (Sokal, 2010). To increase boys' literacy, the survey for this study will ask questions related to the motivation of technology in increasing literacy (Sokal, 2010; Witte, 2007)

\section{The Gender Difference}

Many studies have identified gender differences and a gender gap in literacy (Canadian Council on Learning, 2009; Clark, 2010; Henry et al., 2012; Sadowski, 2010). Alarmingly, by second grade, boys begin to see reading as a feminine activity and need to be exposed to various texts by age 7 or 8 to keep their reading interest broad (Canadian Council on Learning, 2009). Even more concerning is that the level of reading achievement reached by age 14 is the determinant benchmark for predicting educational, social, and economic success (Henry et al., 
2012). In reality, much of what generates interest in reading applies to girls as well as boys (Fisher \& Frey, 2012), but the vast majority of research has focused only on boys.

Stereotypically, boys are "on the go" with short attention spans (Gillespie, 2010). In terms of research, this has actually translated into an effect on leisure reading. Gillespie and Deacon (2010) found that "the influence of interest and text preference on reading comprehension might be more pronounced in boys than in girls." In other words, girls are steadier readers. They are more likely to comprehend a text even if it's not a topic of particularly high interest to them whereas boys need the subject to grab them in order to get much out of it (Clark, 2010; Gillespie, 2010). Almost everyone has greater recall of a book or lecture that captures our interest, but this is especially true for boys. However, another factor may be that since girls typically have wider and more frequent reading experiences, that may allow them to make more connections among books, generating inherent interest (Canadian Council on Learning, 2009). Girls also share about their reading more, leading to greater comprehension and recall (Canadian Council on Learning, 2009).

Some noted differences contributing to the gap include the genre preferences of students and educators. Girls tend to like novels, poetry, and plays while boys prefer cartoons, comics, sports, science fiction and fantasy, hobby-related reading, and non-fiction (Canadian Council on Learning, 2009; Clark, 2010; Hughes-Hassell \& Rodge, 2007; Husband, 2012). Girls like to read for the literary experience while boys read for practicality and information (Husband, 2012). Teachers typically don't teach reading units in those boy categories during a school year (Canadian Council on Learning, 2009). Adding to the difficulty of keeping boys engaged, teachers and librarians often don't view boys' genres as appropriate reading for school, don't 
have it in their classrooms or libraries, and don't particularly promote it (Canadian Council on Learning, 2009).

Boys and girls also use reading differently. Girls use it to connect socially by sharing a reading experience while boys bond by rejecting reading as uncool (Canadian Council on Learning, 2009; Scholes, 2010). This leads to reinforcing behavior in classroom book discussions either in groups or a whole class format. Because the reading purpose and experience are different for the genders, book discussions can simultaneously open girls up and shut boys down, with girls initiating the exclusion of boys' contributions (Husband, 2012). Finally, girls just have a better attitude about reading (Canadian Council on Learning, 2009; Clark, 2010). They like it more and are more motivated to do it on their own time (Clark, 2010; Graham et al., 2008). From early on, girls simply choose to read more for pleasure on a broader variety of topics while boys watch television (Canadian Council on Learning, 2009). Like any activity, the more you do it, the better you get and vice versa (Smith \& Wilhelm, 2004). If boys skip "practice", they won't be ready for the "game." Husband (2012) and Clark (2010) found that "reading frequency is strongly linked to attainment levels" and "reading enjoyment is related to reading attainment." For boys and girls, this becomes a perpetuating cycle (Smith \& Wilhelm, 2004).

Some studies found that boys view reading as a feminine activity and you're not a man if you like to read (Scholes, 2010; Watson et al., 2010). However, a greater number of studies showed that most boys admire literate males and reject reading more because of the "boring" way it's presented in school (Fisher \& Frey, 2012; Kirkland, 2011; Smith \& Wilhelm, 2004). A final weigh-in comes from feminists and postmodernists who believe it's all cultural, that gender is a "fluid" idea and society rudely constricts boys and girls to stereotypical behavior and 
kinds of reading (Frochtwajg, 2009; Moeller, 2011; Williams, 2006). Teachers should not necessarily appeal to boy's interests and the way they're made. Instead, we need to challenge the entire definition and social construct of masculinity (Watson et al., 2010).

In any case, Clark (2010) believes all of this indicates "a wider issue related to boys' motivation and self-esteem with regards to learning in general."

So the existence of gender differences that create a gap has been established, but where does it really come from? Is it cultural or biological? There is no definitive answer yet. On one hand, there is almost a century of research (Henry et al., 2012) to confirm the gap. This would predate video games and other media that have been blamed for the literacy decline and argue in favor of hardwiring. In fact, "most researchers agree that, on average, boys develop the skills associated with reading and writing 12 to 24 months later than girls" (Sadowski, 2010). On the other hand, this research has been all North American and Australian. So perhaps we can say with some confidence that this is at least a Western problem, but to say that the gender gap is as apparent in Asian, African, or Eastern cultures would be speculation as cultural comparisons are beyond the scope of this study.

To narrow the gap, researchers suggest several strategies. Mainly, give boys the books they want (Canadian Council on Learning, 2009). Educators may need to lighten up as to what they consider appropriate academic reading material (Canadian Council on Learning, 2009; Hughes-Hassell \& Rodge, 2007). Boys need exposure and nearly anything that will give them practice is worthwhile (Allyn, 2011; Hughes-Hassell, 2012; Sadowski, 2010).

Some suggestions Gillespie and Deacon (2010) give are to capitalize on current issues and events and popular culture. Also, as teachers get to know their individual students, they should steer the boys toward books that match those boys' interests (Fisher \& Frey, 2012; 
Gillespie, 2010). Since boys are more keyed in to the interest effect, teachers should avoid thinking that everyone will like a certain book just because it's a classic and well-written (Allyn, 2011). Allyn (2011) and others argue forcefully against the whole class novel, stating it's especially detrimental for boys (Elish-Piper \& Tatum, 2006; Fisher \& Frey, 2012).

Gender differences do play into the literacy gap, but 'the complexities surrounding boys' literacy underachievement are multiple and interwoven and cannot be explained solely by gender" (Watson et al., 2010). Seeking to understand significant factors in increasing boys' literacy, the survey for this study will ask questions related to gender differences in reading (Allyn, 2011; Banks, 2011; Canadian Council on Learning, 2009; Clark, 2010; Fredrick, 2006; Henry et al., 2012; Hughes-Hassell \& Rodge, 2007; Scholes, 2010; Watson et al., 2010).

\section{At-Risk Youth and Urban Fiction}

The majority of incarcerated teens in the U.S. are male and minority (Guerra, 2012). Studies have found conflicting results on relationships between literacy and juvenile offenders and recidivism.

Although it cited other studies in its article, the negative study only used 68 individuals in Australia, only a few of whom were Aboriginal or non-native English speakers (Wheldall \& Watkins, 2004). This study focused on the accepted notion that at-risk youth enter detention with low reading abilities but found that a strong majority of detainees were, in fact, functionally literate, some to a high degree. The researchers concluded that getting these youths to read was only one of many factors in keeping kids out of jail (Wheldall \& Watkins, 2004). However, this was a small sample and demographically not comparable to the U.S.'s at-risk population. 
On the positive result side, Guerra (2010) reports that literacy is a major factor in keeping youths out of prison and that reading difficulty is a "leading risk factor for delinquency." She also cites research showing reading instruction is better at reducing recidivism than boot camp style discipline (Guerra, 2012). Finally, she concludes that developing a leisure reading habit is the key to increased literacy, and finding appealing reading material is the critical component (Guerra, 2012). As one school student said, "reading keeps you out of trouble.” (Hughes-Hassell \& Rodge, 2007)

A correctional facility in Florida offers a highly structured reading program (Richter, 2006). Although it doesn't list numbers for long-term results in the article, the supervisors evidently believe in the program and report positive feedback from the participants, again mentioning the self-esteem aspect of increasing literacy. Since the classroom was where many of the offenders originally experienced failure, the educators at the facility seek to help the youths succeed (Richter, 2006).

In a previous section, it was suggested that educators may need to broaden their definition of acceptable literature in order to get boys into books (Canadian Council on Learning, 2009; Hughes-Hassell \& Rodge, 2007). Urban fiction, or street lit, is a controversial genre that deals with the reality of life on the streets (Guerra, 2012). It portrays teens in ghettos and barrios dealing with crime, gang activity, drug use, incarceration and prostitution. The vocabulary is of the streets, as well, using harsh language, non-standard English dialects, and slang. As shown earlier, relatable topics are great motivators for boys to read and urban fiction matches the world they know (Guerra, 2012; Kirkland, 2011). Choice is also important for boys to be interested in reading (Fisher \& Frey, 2012; Kirkland, 2011; Sells, 2009). According to one list from a 
juvenile detention facility, over half of the fiction titles requested from the reading list were street lit as were one third of the non-fiction (Guerra, 2012).

The key debate is whether this class of stories provides the bridge to foster reading habits or romanticizes and reinforces lifestyle stereotypes that got these young men into trouble in the first place (Guerra, 2012).

On the pro side, the gritty street world can be examined from a safe distance and actions evaluated without consequences (Guerra, 2012). Also, since criminal offenders typically lack empathy (Guerra, 2012), being able to identify with characters in a book is valuable. These urban adolescents really need to see themselves in the protagonists and have the story be culturally relevant to be interested (Husband, 2012; Kirkland, 2011; Moeller, 2011; Tatum, 2006). One student in school said "I like reading books about kids my age that have been abandoned and abused. Like I was. It helps me find new ways to deal and confront it." (Hughes-Hassell \& Rodge, 2007). So although it's a classic, Jack London's The Call of the Wild with older white men trekking across the Yukon to pan for gold is probably not going to draw these young men in.

On the other hand, should youths be shielded from this genre so it doesn't validate the negative aspects of their lifestyles? One article cautions against the caricatures one might find in urban fiction (Boone et al., 2010). However, as a librarian noted, "Kids are living stories every day that we wouldn't let them read" (Guerra, 2012). As with most touchy subjects, having competent guidance is critical.

To guide the use of urban fiction, Guerra (2012) asks three questions of any book--does the main character ultimately do something positive for others, grow in self-understanding so as 
to avoid destructive behaviors, and is the book's tone one of hope or despair? For black youths specifically, Tatum (2006) also recommends texts that have a "positive life trajectory."

Guerra (2012) concludes that while she understands the critics of urban fiction, she feels it's worth the risk. To do nothing is worse and with discretion and some criteria for a book to qualify as beneficial, she believes urban fiction can help increase the literacy of incarcerated teens (Guerra, 2012).

To be more applicable to this study of reaching all male adolescents and not just those at risk, Guerra (2012) suggests ways to bring urban fiction into the mainstream classroom such as grouping stories by themes or using a book's individual strengths such as setting, dialect, and plot structures. Books can also be used to discuss societal issues such as power, class, and race (Guerra, 2012). This researcher might add that in a Christian school, while these stories could remove the innocence of many of our students, it could also spur discussion on what kind of world is out there as a mission field, how to reach people with dark life experiences, and the kind of world Jesus dealt with since there is "nothing new under the sun" (Eccl. 1:9 New International Version). Looking for literacy gateways to reach males of all circumstances, the survey for this study will ask questions related to students' interest in characters with similar lifestyles and settings to theirs as a motivation to read (Guerra, 2012).

\section{Graphic Novels}

Although not as controversial as street lit, another category in the debate of what constitutes acceptable classroom literature is graphic novels. These are the grown up descendants of comic books, and the fact that they contain pictures puts them on many educators' suspicion list (Moeller, 2011). In fact, one researcher was denied permission by a 
vice principal to do her study in his school based on the perception of what graphic novels were. After sending some samples for the administrator to read, permission was given (Moeller, 2011). In fact, graphic novels often appear in book format and are either credible works of fiction in their own right or deal with historical issues in story form or are even versions of classics like Shakespeare (Moeller, 2011). They have "complex characters, well-developed story lines, and...foreshadowing and allusion" (Hughes-Hassell \& Rodge, 2007).

In national surveys, graphic novels are quite popular with boys (Brozo, 2012). Because boys do better with non-traditional texts, the pictures in graphic novels hold their interest and greatly aid their understanding of a story's action since they can put the words in the context of a scene (Brozo, 2012).

One teacher used a graphic novel of Romeo and Juliet to help students understand the story. After class discussions, readers' theater, and completing various exercises, the students read the original play with greater enthusiasm and comprehension (Brozo, 2012).

Interesting to note, while boys often see reading in general as "for girls", girls view graphic novels as "boy books.” (Moeller, 2011) However, when girls volunteered for a study and were given graphic novels with characters with whom they could identify, they had a positive reading experience (Brozo, 2012; Moeller, 2011).

As told earlier, girls like to share about their reading which aids comprehension (Canadian Council on Learning, 2009). Boys were found to share about graphic novels, possibly because this format wasn't condoned by educators, which lent it an edgy, breaking-the-rules sort of feel (Moeller, 2011).

One potential downside to graphic novels is that they are associated with "nerd" culture and students don't necessarily like to be seen by their peers reading them for pleasure (Moeller, 
2011; Scholes, 2010). Seeking any genre approach to raise boys' literacy, the survey for this study will ask questions related to students' interest in graphic novels (Brozo, 2012; Moeller, 2011).

\section{Urban Youth}

Although the term "urban youth" refers to all inner-city minorities, most research literature has been about African Americans. African American males are caught in a complex cycle involving academics and culture. Low teacher expectations, lack of parental involvement, negative peer pressure, lack of male role models, high rates of homicide, incarceration, unemployment, and poverty all lead to black males disengaging from school (Boone et al., 2010; Haddix, 2009; Husband, 2012; Tatum, 2003). This leads to more referrals for discipline, more labels of "at-risk," and more time spent in remedial settings (Haddix, 2009; Husband, 2012; Tatum, 2003; Tatum, 2006). Even if they obtain a high school or college degree, black males may still experience a lack of direction for their future and feel their time in school was wasted (Tatum, 2003). Outside the academic setting, African American males encounter other barriers such as self-concept and identity issues (Tatum, 2006). Their "cultural-specific coping mechanisms" include acting tough and shutting down and dissociating from school (Tatum, 2006).

There is clearly more to this problem than just literacy, but that is the focus of this study and one factor that can make a difference. One mother believed her son, who had been held back several times before eighth grade because of low reading competency, would be dead or in prison within three years if he didn't become a better reader (Tatum, 2008). 
In the early 1800s, young African American men created literary societies in which they would engage all manner of great texts for the purpose of not only educating themselves, but to impact history with scholarly contributions and effect change in the African American community (Tatum \& Muhammad, 2012). Language is a central tenet of African American culture (Haddix, 2009). Not just written language, as this study of literacy emphasizes, but a complete package of spoken and written expression utilizing specific vocabulary and themes and delivered with creative presentation (Haddix, 2009). From the literary societies of the 1800s through the Harlem Renaissance and what James Weldon Johnson called the "flowering of Negro literature" to the memoirs and essays of the 1960s and 1970s, African Americans used language to "reclaim authority over themselves" and for "liberation, protection, and security" (Tatum \& Muhammad, 2012). The reasons why the state of African American literacy has changed were not specifically found in the research and are outside the scope of this study. However, this present study will attempt to address the current situation.

Early on, several factors crop up to put black males behind in literacy. Some are common to all boys and some are unique to minorities. In general, boys prefer non-fiction, superhero stories, scary fairy tales, male characters, and the like (Canadian Council on Learning, 2009; Clark, 2010; Hughes-Hassell \& Rodge, 2007; Husband, 2012). Most children's literature through elementary school is narrative fiction of the type considered "appropriate" by teachers (Canadian Council on Learning, 2009). This gives girls an early boost in reading and, by the late elementary grades, one study found that girls were taking charge of literature discussion groups and demoting or ignoring the boys (Husband, 2012). Additionally, black boys didn't find the characters or settings socially or culturally relevant (Husband, 2012; Kirkland, 2011; Moeller, 2011). Many people will not read a book if they don't identify with the characters, but in a 
typical educational environment, minorities have even less access to texts that relate to them and African American boys particularly seem to need that connection (Canadian Council on Learning, 2009; Guerra, 2012; Husband, 2012; Kirkland, 2011; Moeller, 2011).

Throughout several articles, a central demand for African American males to engage in reading was to be able to find themselves in the text, to have it reach into their world and be relevant to their culture and to add to their sense of self (Boone et al., 2010; Fredrick, 2006; Haddix, 2009; Husband, 2012; Kirkland, 2011; Tatum, 2006). As one author put it, the black males he studied "wore books like clothes. [They] read what fit [them] and did not read what didn't" (Kirkland, 2011). Texts that lack this connection are reacted to with hostility, suspicion of brainwashing, and viewed as potential attacks on identity and masculinity (Kirkland, 2011; Tatum, 2006). Tatum $(2008,2006)$ calls the positive literature "enabling texts." An enabling text "is one that moves beyond a solely cognitive focus — such as skill and strategy development — to include a social, cultural, political, spiritual, or economic focus" (Tatum, 2008). For African Americans, meaningful texts have four qualities. They contribute to a healthy psyche, focus on a collective struggle, provide a road map for being, doing, and acting, and provide modern awareness of the real world (Tatum, 2008).

Among minorities, the strength of this need for connection seems to be unique to African Americans. In one study with a primarily Latino student population, only $31 \%$ of males said they liked to read about people or characters like them, 38\% liked to read about people their age who have done amazing things, and $28 \%$ like to read about people or characters their age who were wrestling with issues such as drug abuse or crime (Hughes-Hassell \& Rodge, 2007). In addition, when asked to list their favorite books, students only mentioned a few multicultural titles or books in the street lit genre (Hughes-Hassell \& Rodge, 2007). 
One might question how to find the balance between preserving a cultural identity versus focusing so heavily on cultural heritage that people are unable to engage in the greater world. Using literature, Professor Tatum has held discussions in his classes on the idea of African Americans integrating or separating. Some students argued for separation while others remarked "we're all human" and wondered why they were focusing so specifically on things "black" (Tatum, 2006).

You think your pains and heartbreaks are unprecedented in the history of the world, but then you read. It was books that taught me that the things that tormented me were the very things that connected me with all the people who were alive, or who have ever been alive. James Baldwin Either way, the texts Professor Tatum chose engaged the students and fostered critical thinking (Tatum, 2006).

Minorities also face the stigma of "acting white," defined again as paying a social price in popularity for succeeding academically (Fryer, 2006). This mainly held true for minorities in desegregated public schools who had the most interracial friendships. As their grades went up, their friendships eroded. In this breakdown, as well, males paid the highest price defined as having the fewest friends coupled with the highest GPA. However, in segregated or private schools, there was no social punishment for academic success (Fryer, 2006). All the social implications and possible solutions to this behavior are outside the scope of this study, but educators should consider the dynamics of their own student populations as they seek strategies for increasing male literacy.

An earlier section of the review discussed the impact of parental expectations and cultural capital (Bowen et al., 2012; Harris \& Graves Jr., 2010). For low SES and minority students, the 
results were mixed. In some cases, the researchers believed that academic achievement did not increase because there was a gap between what the parents had themselves accomplished in school and what they were asking their children to do (Banks, 2011; Bowen et al., 2012). The children felt the parents lacked credibility because the adults had not performed well in school yet were setting the bar high for their children (Banks, 2011; Bowen et al., 2012). Other students reacted favorably to the high expectations and strove for success (Bowen et al., 2012). In addition, high parental expectations caused students to avoid problem behaviors such as associating with troublesome friends (Bowen et al., 2012). The study concluded that all things considered, what students believed their parents expected of them was a strong predictor of behavior (Bowen et al., 2012).

The bridge between home and school is crucial (Hughes-Hassell, Koehler, \& Barkley, 2010). Harris and Graves (2010) recommended using newsletters, electronic announcements, and PSAs through African American media outlets to raise parents' awareness of the value of deliberately transferring cultural capital and its impact on reading achievement. Although financial resources play some part in what activities a family can do, the study suggested that lower SES parents can have just as much impact on their children by spending similar time doing whatever they can as long as they are interacting (Harris \& Graves Jr., 2010).

General solutions to improving African American male literacy are for teachers to examine their perceptions and stereotypes of black male students, engage them with more relevant literature in more meaningful and creative ways, rethink discipline policies, and add cultural training to preservice teacher programs (Boone et al., 2010; Husband, 2012; Tatum, 2003). 
Black boys will read. But to get them off to a flying start, we've got to give them books that remind them of home--who they are. When this happens, they fly through books--even the most challenged readers. They hunger for the work like a homeless man finally getting a meal that's weeks overdue . (HughesHassell et al., 2010)

Seeking to understand what would bring African Americans to books, the survey for this study will ask questions of all students related to parental involvement and interest in a text, but will examine the results by race even though the African American sample is small $(N=14)$.

\section{Summary}

To investigate the degree to which any of these factors influence male adolescent literacy in this researcher's school, the survey will ask questions about motivation or what sparks a boy's interest in a book (Elish-Piper \& Tatum, 2006; Fisher \& Frey, 2012; Graham et al., 2008; Hughes-Hassell \& Rodge, 2007; Husband, 2012; Kirkland, 2011; McDowell et al., 2011; Sells, 2009), competence and self-efficacy (McDowell et al., 2011; Smith \& Wilhelm, 2004), the perceived feminization of reading and gender differences including genre preferences (Canadian Council on Learning, 2009; Clark, 2010; Hughes-Hassell \& Rodge, 2007; Moeller, 2011; Werderich, 2010), influences on boys' choice of text (Allyn, 2011; Boone et al., 2010; Fisher \& Frey, 2012; Guerra, 2012; Werderich, 2010) and desire to read including teachers, parents, and other influential adults (Henry et al., 2012; Hughes-Hassell \& Rodge, 2007; Werderich, 2010), what boys believe constitutes legitimate reading including graphic novels and the internet (Canadian Council on Learning, 2009; Hughes-Hassell \& Rodge, 2007; Moeller, 2011), and the use of technology to entice boys to read (Sokal, 2010; Witte, 2007). Further questions will focus 
on African Americans with respect to cultural capital and interest in a text (Harris \& Graves Jr., 2010; Kirkland, 2011; Moeller, 2011).

\section{Chapter three}

\section{Method}

\section{Participants}

Participants were 137 enrolled seventh and eighth graders at a private, suburban Christian school in Columbus, Ohio. This represented $90 \%$ of the seventh and eighth grade student body. There were 76 males and 61 females between the ages of 12 and 15. Racial demographics were 68\% Caucasian, 10\% African American, 2\% Asian, 2\% Hispanic, 2\% American Indian, 2\% Native Hawaiian or Pacific Islander, and 2\% Multi-ethnic. Informed consent was obtained for all participants and no compensation was given.

\section{Instruments}

The researcher designed an online survey with 34 questions on a Likert scale using a mixed-method research approach with dominant-status concurrent design. This design was chosen because the weight on quantitative data was heavier than on the qualitative and all questions were answered at the same time with no follow-up phases. The survey contained an open-ended question at the end which sought complementarity, and each student took the entire survey at one sitting. The intent of complementarity is to "seek elaboration, enhancement, illustration, and clarification of the results from one method" (Johnson \& Christensen, 2008b). In choosing to add an open-ended question for complementarity, along with quantitative data, 
this researcher wanted to give the participants a chance to speak freely about their views on reading.

Studies in published literature have used anywhere from 5 questions in a qualitative, interview style study to 50 or more questions in quantitative studies using adolescents (Bowen et al., 2012; Bozack, 2011; Kirkland, 2011). Time did not permit long, qualitative interviews, and this researcher believed that the 34 quantitative questions used in this present study appropriately met the middle range of those prior studies.

Questions 1 and 11-15 were chosen on the idea of transmission of cultural capital and parent involvement and modeling (Bowen et al., 2012; Harris \& Graves Jr., 2010; HughesHassell \& Rodge, 2007; Lutz, 1986).

1. (Q1) Reading on your own outside of school is important.

11. (Q33) Influential people in my life believe reading for fun is important.

12. (Q34) My parents read to me frequently when I was young.

13. (Q35) I see my parents read in their spare time.

14. (Q36) I see my siblings read in their spare time. (This question included an N/A option)

15. (Q37) I see influential people in my life read in their spare time.

Questions 5 and 6 were also about cultural capital but specifically with the idea of African Americans reading the urban fiction genre and supposedly wanting characters and lifestyles with which they could identify (Guerra, 2012; Hughes-Hassell \& Rodge, 2007). Those questions also addressed motivation (Bozack, 2011; Fisher \& Frey, 2012; Werderich, 2010). 
5. (Q10) I like to read about characters who have a similar lifestyle or history as I do.

6. (Q11) I like to read about characters who are completely different from me.

Questions 3 and 4 were to confirm the genre preferences of males and females (Canadian Council on Learning, 2009; Clark, 2010; Hughes-Hassell \& Rodge, 2007; Husband, 2012; Sells, 2009).

3. For fun, I prefer to read (please answer both) fiction $(\mathrm{Q} 3)$ nonfiction (Q4)

4. For fun, I prefer to read books (Q5) magazines (Q6) newspapers (Q7) graphic novels or comic books (Q8) websites or social media $(\mathrm{Q} 9)$

Questions 7-10 and 26 related to motivation to read (Clark, 2010; Fisher \& Frey, 2012; Gillespie, 2010; Kirkland, 2011; Werderich, 2010).

7. The following are important to me when choosing something to read: The cover looks interesting (Q12) 
The summary on the back sounds good (Q13)

A friend recommended it (Q14)

A teacher/librarian recommended it (Q15)

A parent recommended it (Q16)

An adult friend recommended it (Q17)

I heard about it on social media (Q18)

8. I chose the last book I read for fun because

The cover looked interesting (Q19)

The summary on the back sounded good (Q20)

Someone I know recommended it (Q21)

I heard about it on social media (Q22)

9. I would be MORE likely to read a book if recommended by a(n)

friend $(\mathrm{Q} 23)$

teacher/librarian (Q24)

parent $(\mathrm{Q} 25)$

adult friend (Q26)

website or social media (Q27)

10. I would be LESS likely to read a book if recommended by a(n)

friend $(\mathrm{Q} 28)$

teacher/librarian (Q29)

parent $(\mathrm{Q} 30)$

adult friend (Q31)

website or social media (Q32) 
26. (Q53) I would be more likely to read a book for fun if I had interesting questions I wanted to find answers for.

Questions 9 and 10 were more specifically about who best influences an adolescent to read (Hughes-Hassell \& Rodge, 2007).

9. I would be MORE likely to read a book if recommended by a(n) friend $(\mathrm{Q} 23)$ teacher/librarian $(\mathrm{Q} 24)$ parent $(\mathrm{Q} 25)$ adult friend (Q26) website or social media (Q27)

10. I would be LESS likely to read a book if recommended by a(n) friend $(\mathrm{Q} 28)$ teacher/librarian (Q29) parent $(\mathrm{Q} 30)$ adult friend (Q31) website or social media (Q32)

Some research recommended a broader definition of leisure reading and implied students may not be giving themselves credit for doing as much reading as they actually are based on the medium, so questions 16-19 were meant to address what students deemed legitimate reading (Canadian Council on Learning, 2009; Moeller, 2011). 
16. (Q38) Magazines count as legitimate reading.

17. (Q39) Newspapers count as legitimate reading.

18. (Q40) Graphic novels or comic books count as legitimate reading.

19. (Q41) Internet surfing counts as legitimate reading.

One fairly accepted belief is that many boys see reading as a feminine activity (Canadian Council on Learning, 2009; Guerra, 2012; Watson et al., 2010). Questions 20-24 sought to confirm that perception.

20. (Q42) Girls are better readers than boys.

21. (Q43) Reading is more of a girl activity.

22. (Q44) Most of the books for my age are written for girls.

23. (Q45) Teachers mostly pick books that girls like.

24. (Q46) Boys can read as well as girls.

Question 27 addressed a proposed solution of encouraging more male teachers and role models to improve boys' literacy (Canadian Council on Learning, 2009; Henry et al., 2012; Sokal, 2010; Werderich, 2010).

27. (Q54) If someone of the same gender recommended something good to read, I would be more likely to read it. 
Competence and self-efficacy were approached in Questions 25, 30, and 31 (Canadian Council on Learning, 2009; Clark, 2010; Graham et al., 2008; McDowell et al., 2011; Smith \& Wilhelm, 2004).

25. I don't read for fun more often because

I can't find anything that interests me (Q47)

I don't like to read (Q48)

I don't have time (Q49)

reading is difficult and takes too long $(\mathrm{Q} 50)$

reading isn't that important $(\mathrm{Q} 51)$

I don't believe I would be able to understand or finish the book (Q52)

30. (Q59) I am confident in my reading ability.

31. (Q60) I wish I could read better.

Questions 28 and 29 addressed the presentation of literature in electronic formats to see if that would elevate interest (Sokal, 2010; Witte, 2007).

28. Evaluate the following statements:

I would read more for fun if I could use audiobooks (Q55)

If I used an audiobook, I would also follow along in the paper book (Q56)

Listening to audiobooks WITHOUT following the paper book counts as reading (Q57) 
29. (Q58) I would read more for fun if I could do it electronically like on my phone or using an e-reader such as a Kindle.

Finally, Questions 32-34 were just to confirm the library circulation numbers that piqued the researcher's interest in this whole project (Fisher \& Frey, 2012).

32. (Q61) I read LESS for fun than I did two years ago.

33. (Q62) I read about the SAME amount for fun as I did two years ago.

34. (Q63) I read MORE for fun than I did two years ago.

The survey also included an open response section at the end for any comments about the survey or reading in general.

40. (Open-ended) Is there anything else you would like to say about books, reading, this survey, or what it would take to get you to be a more frequent reader?

\section{Procedure}

The survey was administered to students during their Language Arts class periods 1, 3, 4, 6, or 9 from Wednesday through Friday in late May 2014. Class periods began at 8:45 A.M., 10:13 A.M, 10:58 A.M., 12:24 P.M., and 2:35 P.M. The survey was uploaded to the researcher's website which was easily accessed from the school computers. Students used laptops from a laptop cart. Allowance was made for multiple responses from the same IP address. This was done so that more than one student could use the same computer since they have individual 
logins. Otherwise, only one class of students could use the laptops to take the survey. The other five classes would have had to use other computers on their own time, most likely at their home, which adds confounded variables due to the uncontrolled environment and lessens the likelihood of as many students completing the survey thereby reducing the sample size. The survey was set with a closing date so outside web traffic would not inadvertently access the survey.

The researcher defined "leisure reading" and emphasized that responses were anonymous and students should answer honestly. Students averaged ten minutes to complete the survey. The longest time was 37:30 and the shortest was 5:09. Boys averaged 10 1/2 minutes and girls averaged $91 / 2$ minutes. While 138 students began the survey, only 137 finished as one student apparently abandoned after five questions. SurveyMonkey, the website hosting the survey, then compiled the data into a form that could be transmitted to a statistician.

Each student worked on an individual laptop computer and was told not to discuss the questions or their thoughts with other students. However, confounding variables include two students who took the survey with the Remedial Resource teacher in her room so this researcher was not present. Also, students from the morning classes could have discussed the survey with students who had yet to take it in the afternoon. It is also possible that even within the same class period, students could have whispered to one another. Since the survey was administered over several days to the various classes due to the number of laptops available at one time, students from an earlier day could have discussed the survey with students who had yet to take it. Finally, although the researcher attempted to set the parameters of the survey so that students would be required to answer all questions, the statistician revealed that a few answers were left blank, necessitating the removal of that answer in the data. 


\section{Chapter four}

\section{Data Analysis}

Using the statistical program Minitab, coded results were run through an Analysis of Variance (ANOVA) with a 95\% confidence level $(N=137 ; \mathrm{p}<=0.05)$. ANOVAs varied among one-way, two-way, and two-way with interaction. Three main combinations were run. First, all questions were broken down by gender. Next, questions 1-11 were examined between African American males and all other races. Finally, questions 33-37 were examined between all African Americans and all other races.

Although the original survey format contained 34 literacy questions and 5 demographic questions, statistical software required each option within a question to be assigned its own number. For instance, survey question \#3 had two choices for genre preference. These became numbers Q3 and Q4 in the statistical output. Survey question \#4 had five choices for reading preference. Therefore, these became Q5, Q6, Q7, Q8, and Q9 in the statistical output. The software, then, coded a total of 63 questions. Question numbers referred to throughout the rest of this analysis are by the statistical number, not the original survey number (see Appendix A).

The specific Mean numbers for each gender and race as well as the actual p-values can be found in Appendix C.

For a broad look at how all students responded to each question, Appendix B shows a ranking of all questions by strength of agreement and disagreement.

The researcher gratefully acknowledges the assistance of Dr. William Harper, Professor of Mathematical Sciences at Otterbein University, in processing and interpreting the data. 
Results

\section{Data Results}

Pie charts are only displayed for questions that had statistically significant differences.

\section{Gender}

Although the Mean for girls was slightly higher, no significant difference was found in students believing that leisure reading was important. Again, with a higher Mean for girls, both genders generally agreed they would read more for pleasure if they had more time.

According to Mean, both genders actually preferred fiction overall to nonfiction, which was contrary to most literature (Canadian Council on Learning, 2009; Clark, 2010; HughesHassell \& Rodge, 2007; Husband, 2012; Werderich, 2010), but there were statistically significant differences $(\mathrm{p}<=0.05)$ in the strength of preferences at the $95 \%$ confidence level. Girls did, in fact, prefer fiction and boys preferred nonfiction to a greater degree (Figs. $1 \& 2$ ).

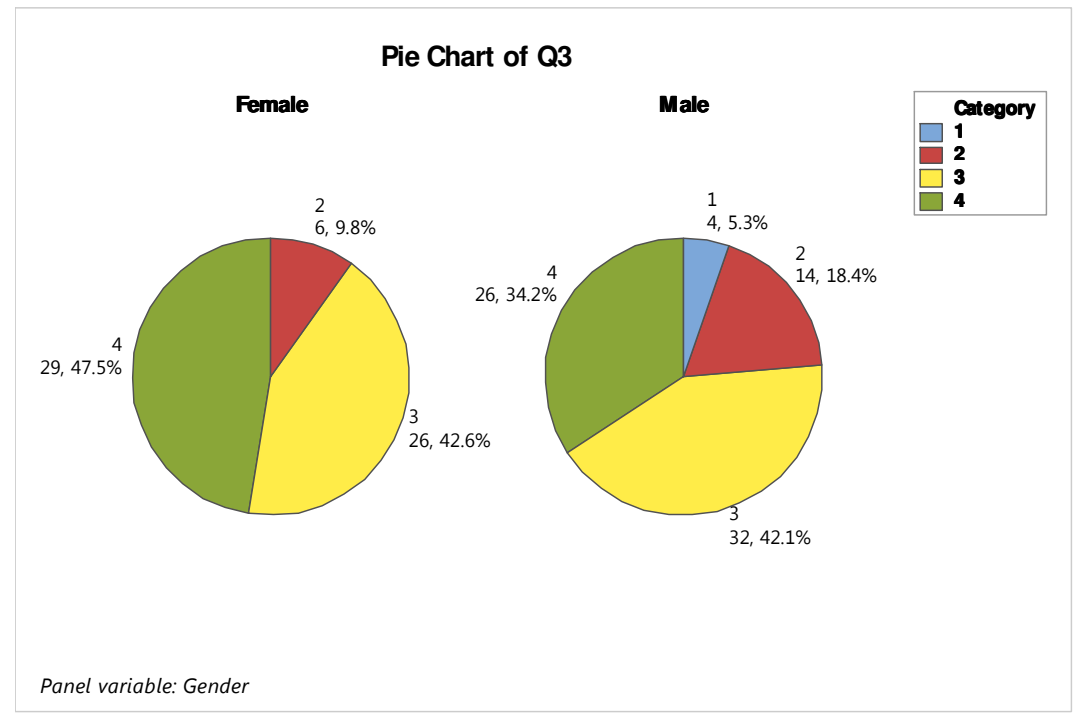

Figure 1- For fun, I prefer fiction

(1-Strongly Disagree 2- Disagree 3-Agree 4- Strongly Agree) 


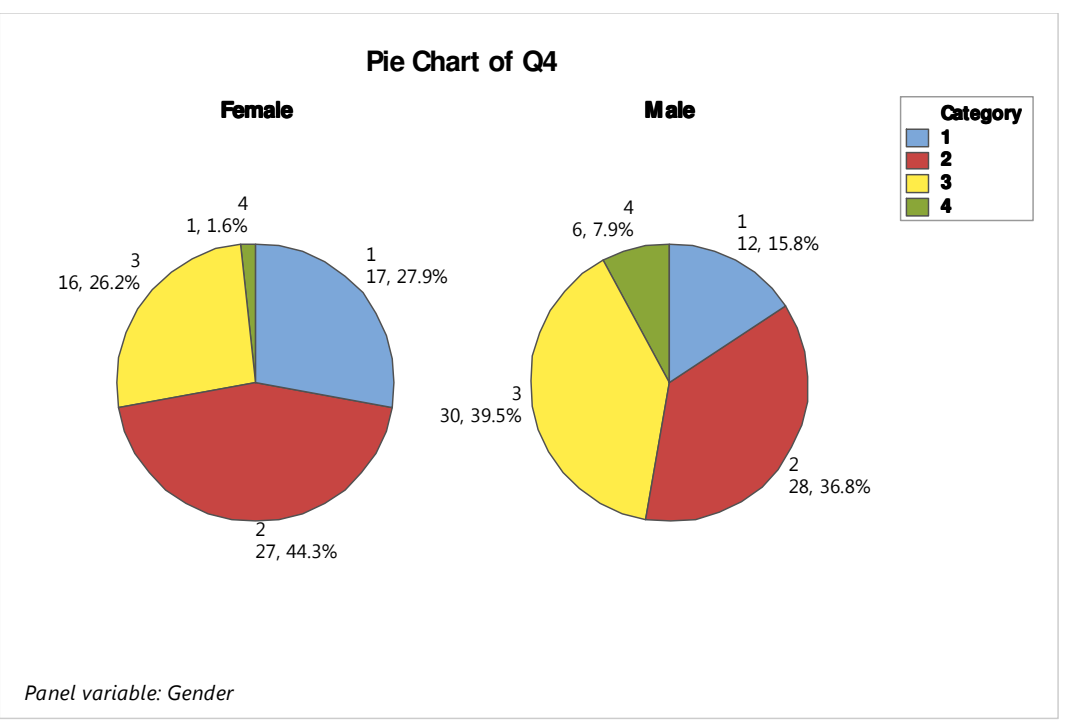

Figure 2- For fun, I prefer nonfiction

\section{(1-Strongly Disagree 2- Disagree 3-Agree 4- Strongly Agree)}

In terms of the format for reading, while books topped all categories without significant difference, girls significantly preferred magazines and boys chose newspapers and graphic novels which was in line with the literature (Figs. 3-5) (Canadian Council on Learning, 2009; Clark, 2010; Hughes-Hassell \& Rodge, 2007; Husband, 2012; Werderich, 2010).

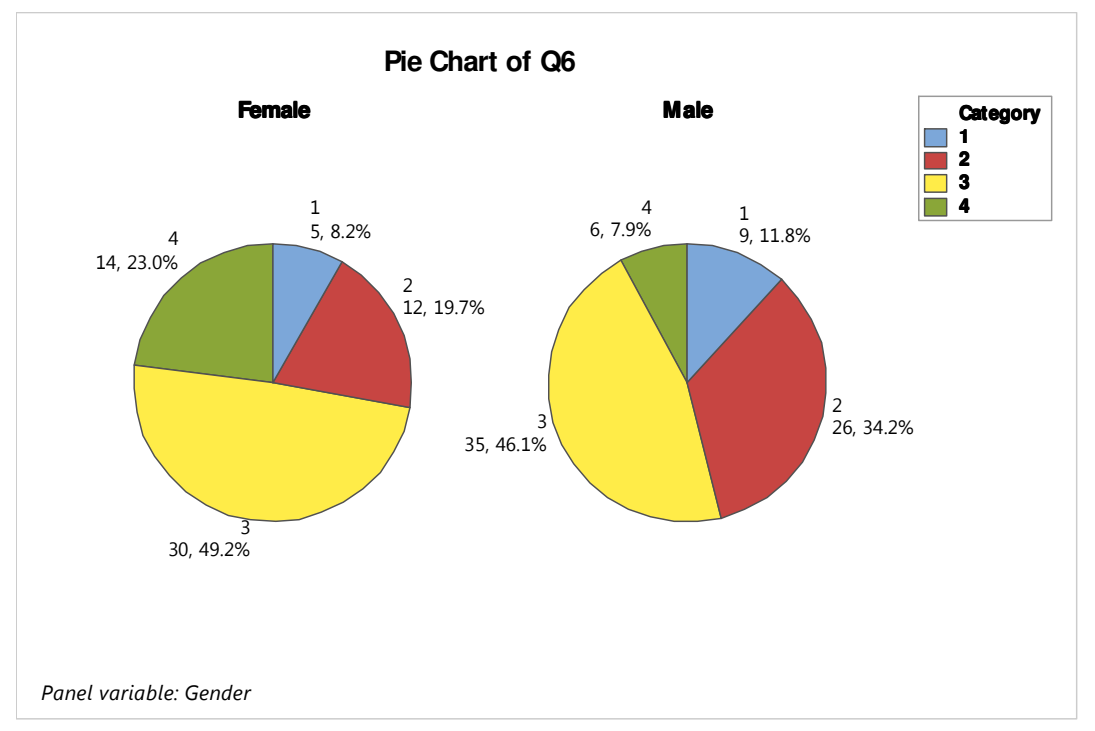

Figure 3- For fun, I prefer magazines 


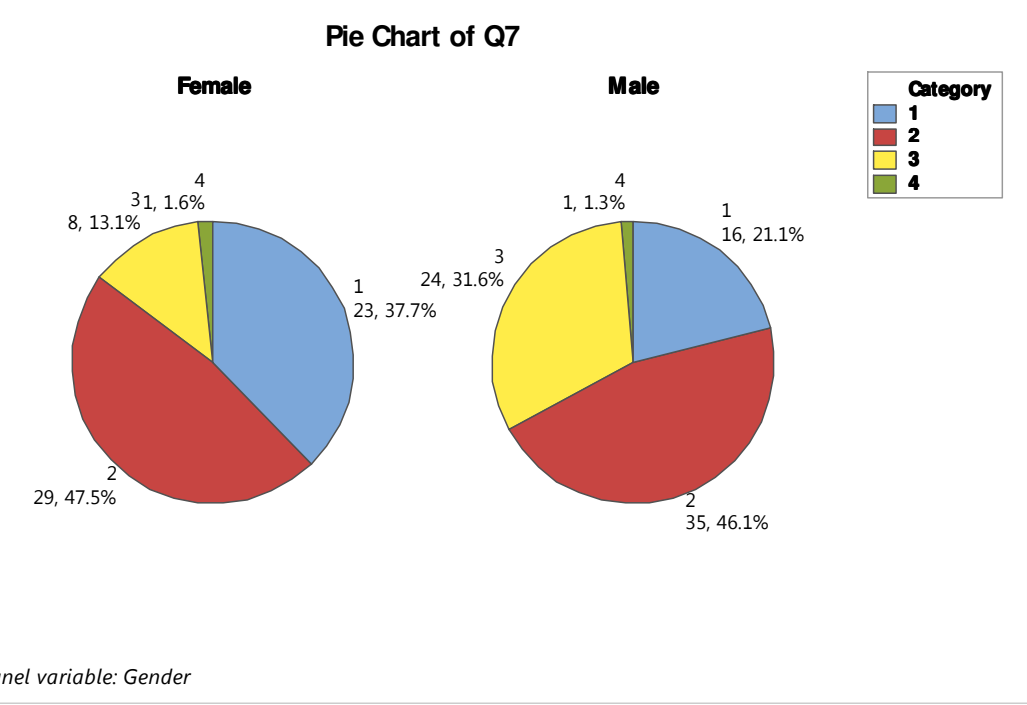

Figure 4- For fun, I prefer newspapers

(1-Strongly Disagree 2- Disagree 3-Agree 4- Strongly Agree)

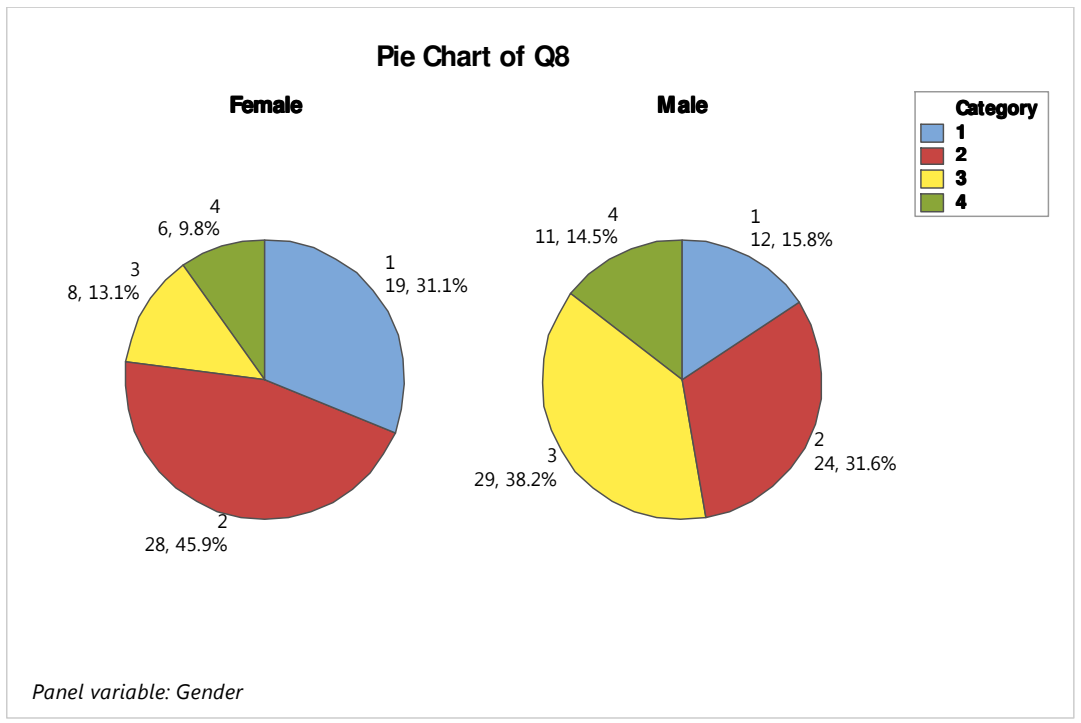

Figure 5- For fun, I prefer graphic novels or comic books

(1-Strongly Disagree 2- Disagree 3-Agree 4- Strongly Agree) 
Although not statistically significant, girls actually gravitated toward websites and social media, contradicting the idea that technology is a male dominated area and that technology is a gateway to get boys to read (Sokal, 2010).

In terms of what is important to adolescents when choosing something to read, no significant difference was found among an interesting cover, a summary of the book, or recommendations from friends, parents, teachers, or adult friends. The only significant difference was that boys were much less likely to follow the recommendation from websites or social media, again a surprise contradiction to the literature (Fig. 6) (Sokal, 2010).

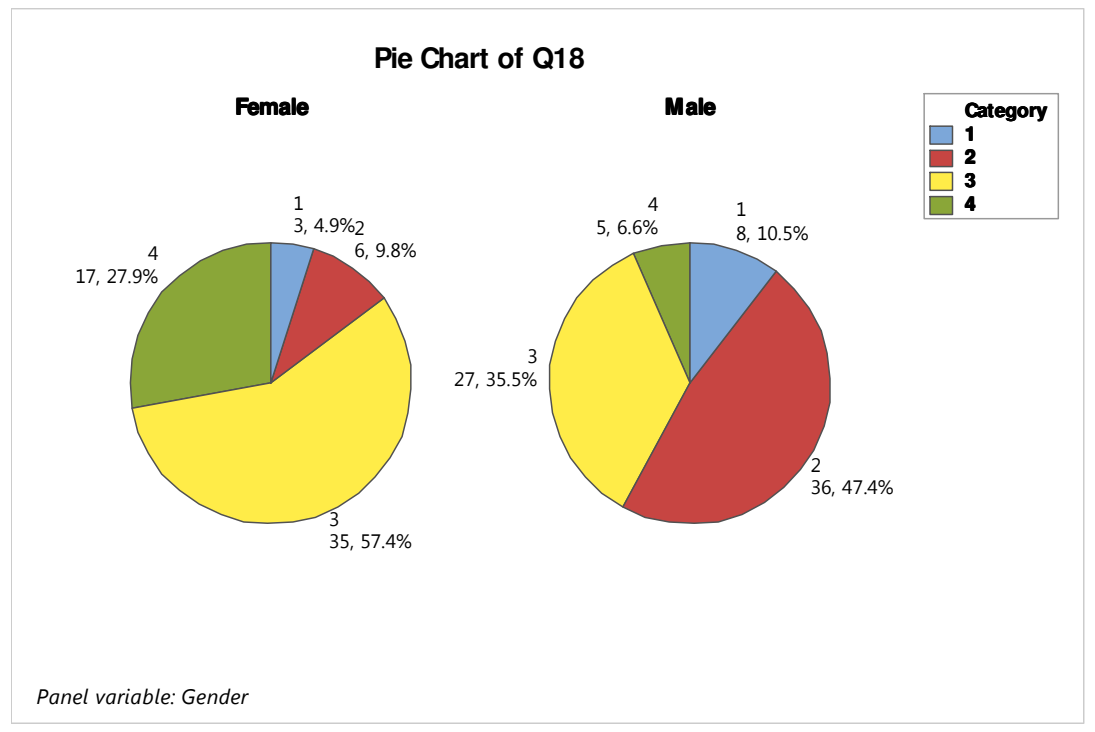

Figure 6- The following are important to me when choosing something to read: I heard about it on social media

$$
\text { (1- Strongly Disagree 2- Disagree 3-Agree 4- Strongly Agree) }
$$

For the factors that influenced their last choice of book, boys responded significantly less favorably to a summary of the book, a personal recommendation, and information from websites and social media (Figs. 7-9). 


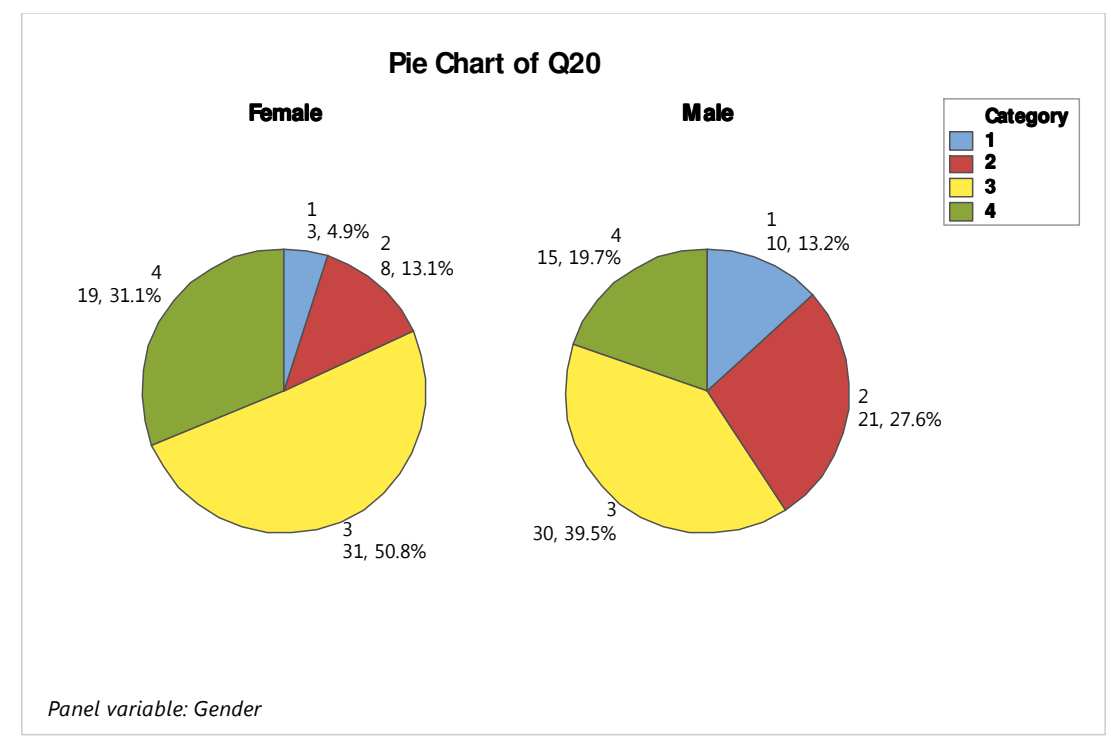

Figure 7- I chose the last book I read for fun because the summary on the back sounded good (1-Strongly Disagree 2- Disagree 3-Agree 4- Strongly Agree)

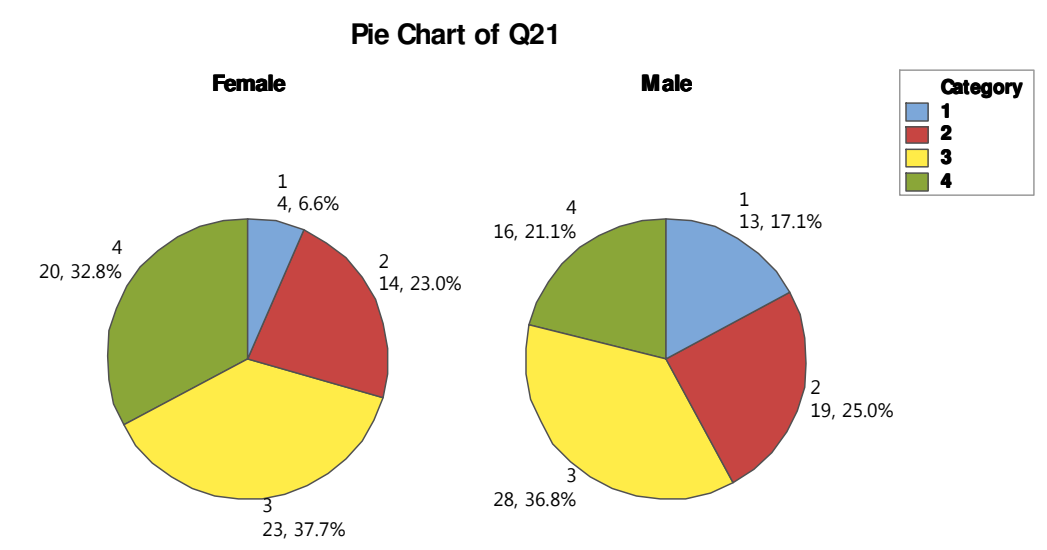

Panel variable: Gender

Figure 8- I chose the last book I read for fun because someone I know recommended it
(1- Strongly Disagree
2- Disagree
3- Agree
4- Strongly Agree) 


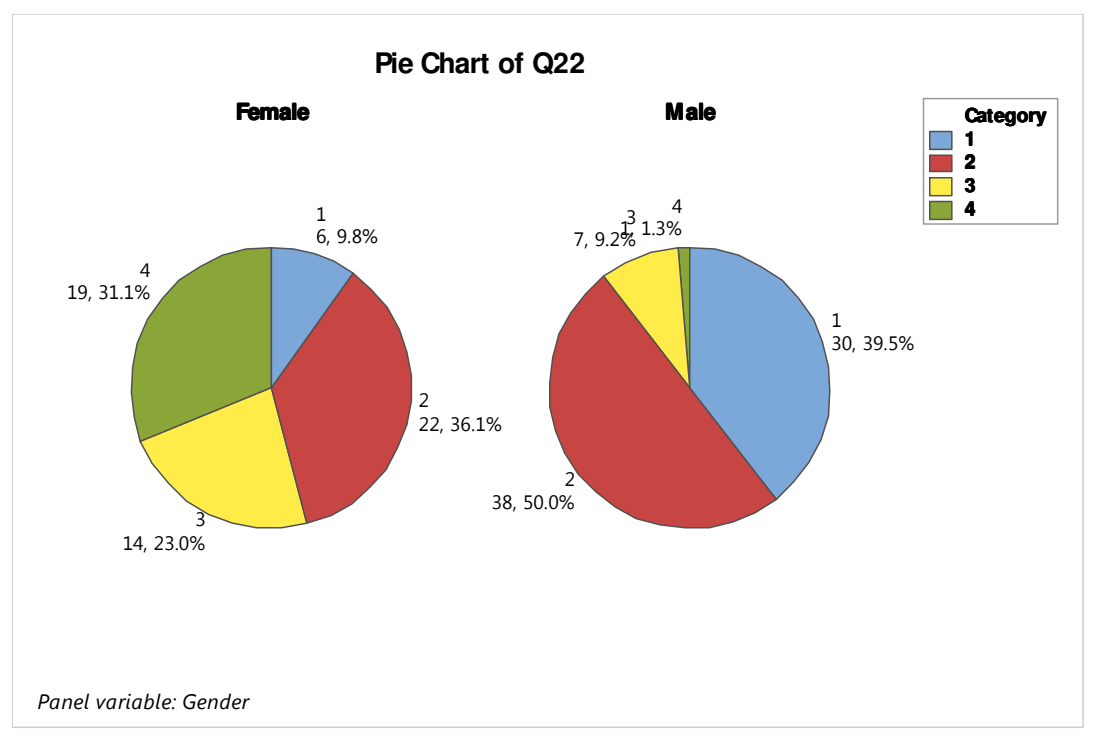

Figure 9- I chose the last book I read for fun because I heard about it on social media

$$
\text { (1- Strongly Disagree } \quad 2 \text { - Disagree } \quad 3 \text { - Agree } \quad 4 \text { - Strongly Agree) }
$$

For whose recommendation would more likely influence an adolescent to read a book, no significant difference was found for friends, teachers, or adult friends. However, males were significantly more likely to take a parents' recommendation, and girls would respond to websites or social media (Figs. $10 \& 11$ ).

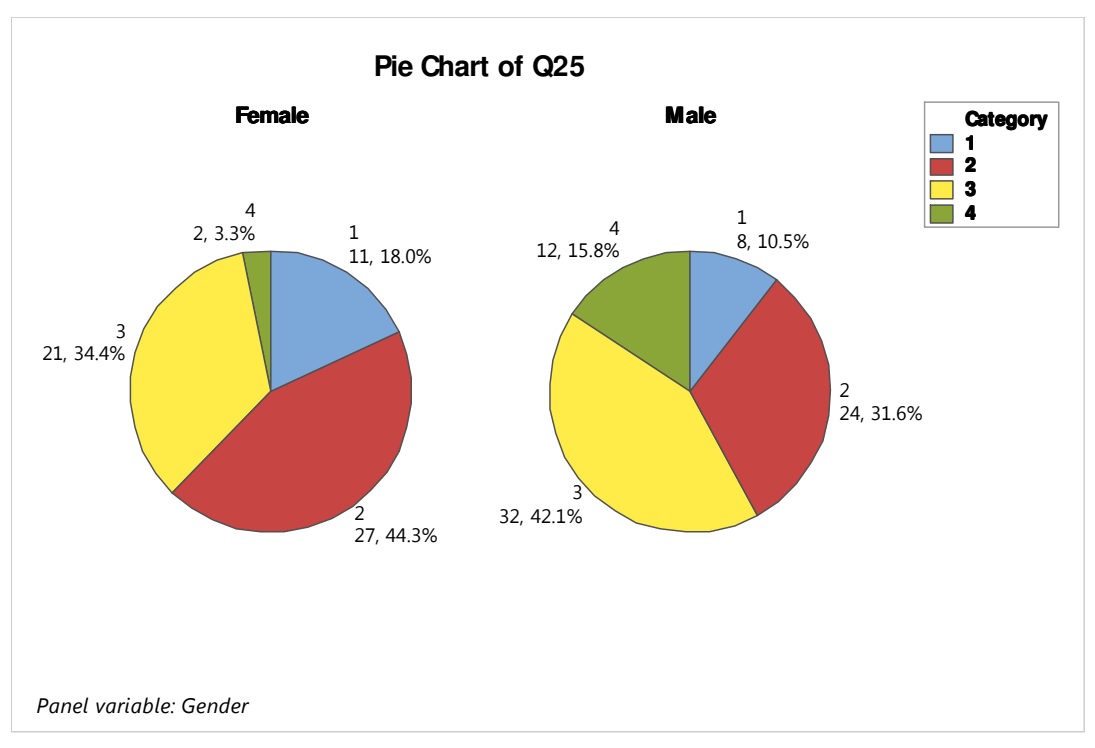

Figure 10- I would be MORE likely to read a book if recommended by a parent 


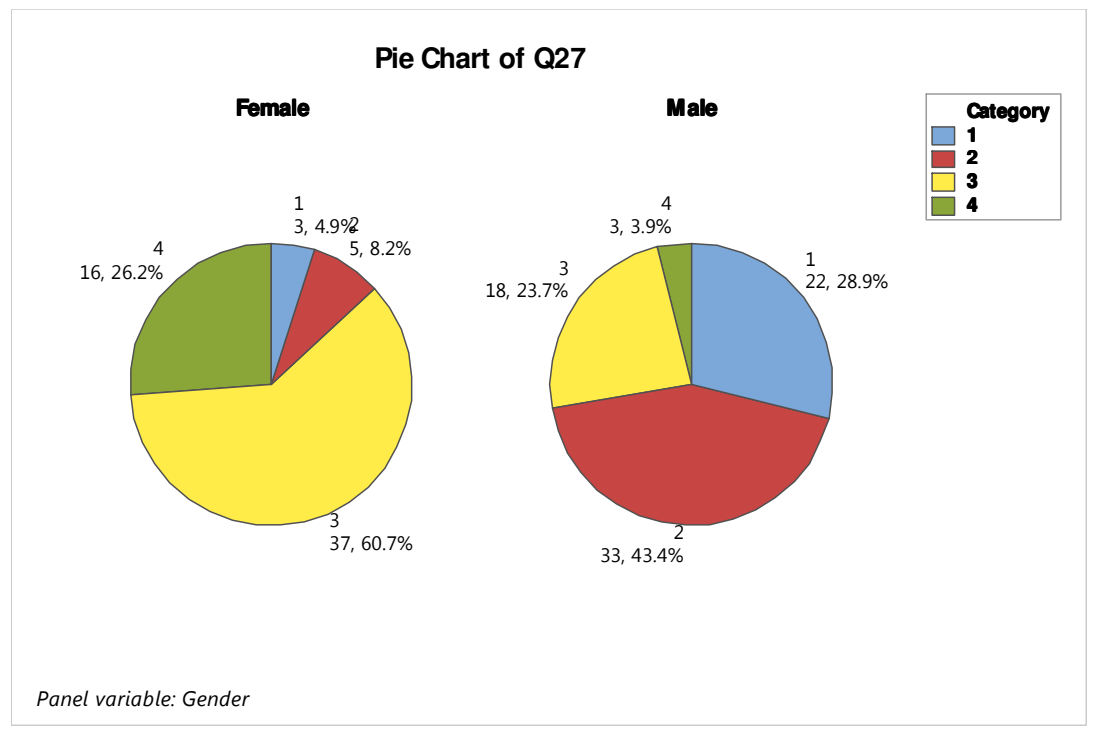

Figure 11- I would be MORE likely to read a book if recommended by a website or social media (1- Strongly Disagree 2- Disagree 3- Agree 4- Strongly Agree)

For whose recommendation would make it less likely that the adolescent would read, no significant difference was found for any category except websites or social media, where boys again by a wide margin unexpectedly did not care for the technology (Figure 12) (Sokal, 2010).

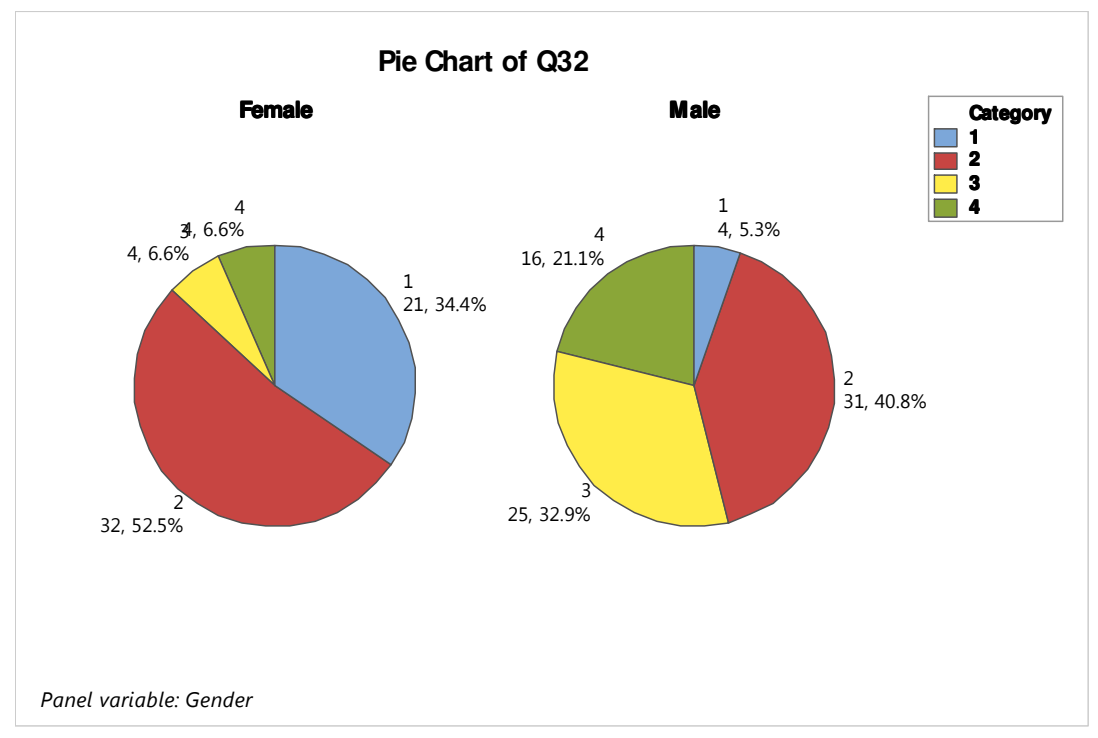

Figure 12- I would be LESS likely to read a book if recommended by a website or social media 
In terms of what constitutes legitimate leisure reading material, boys predictably found newspapers and graphic novels significantly more suitable than did girls (Figs. 13 \& 14) (Canadian Council on Learning, 2009; Clark, 2010; Hughes-Hassell \& Rodge, 2007; Husband, 2012; Werderich, 2010). There were no significant differences for magazines or internet surfing.

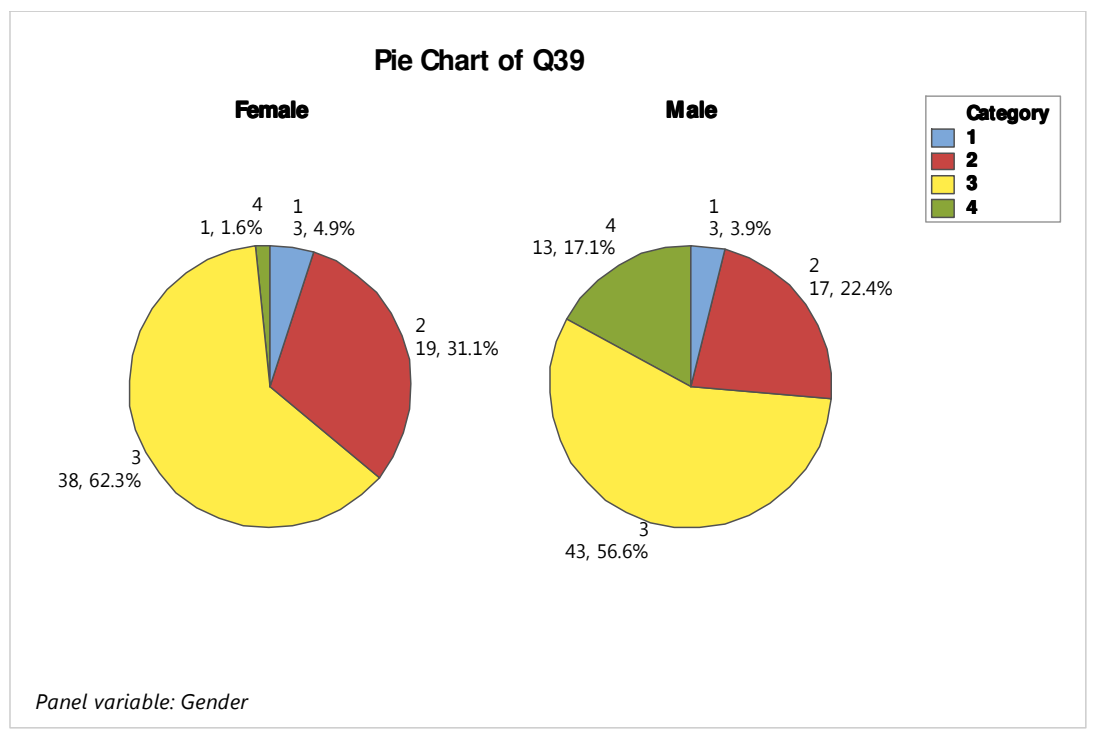

Figure 13- Newspapers count as legitimate reading (1- Strongly Disagree 2- Disagree 3-Agree 4- Strongly Agree) 


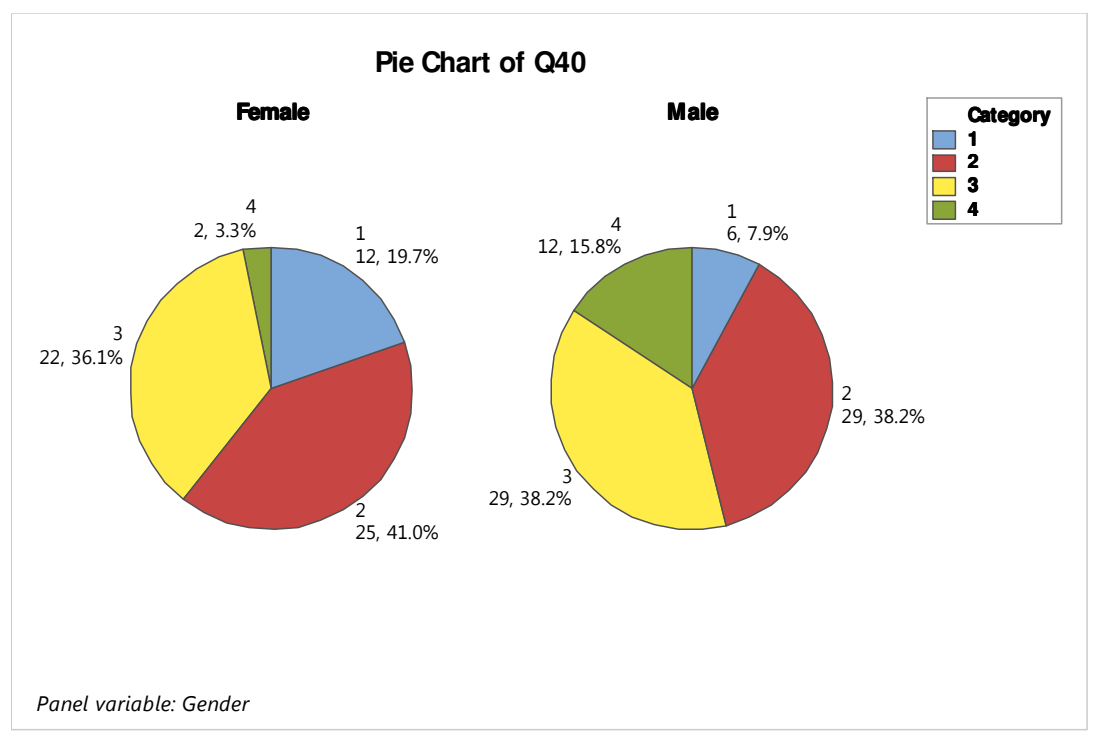

Figure 14- Graphic novels or comic books count as legitimate reading (1- Strongly Disagree 2- Disagree 3- Agree 4- Strongly Agree)

Many studies found that reading was perceived as a feminine activity (Canadian Council on Learning, 2009; Moeller, 2011; Werderich, 2010). While girls in this study did significantly believe that they were better readers than boys (Fig. 15), both groups disagreed overall and no significant difference was found in the idea that reading was more of a girl activity. Significantly, girls did believe that more books for adolescents were written for females (Fig. 16), but neither group believed that teachers selected more female-oriented books and no significant difference was found (Canadian Council on Learning, 2009). 


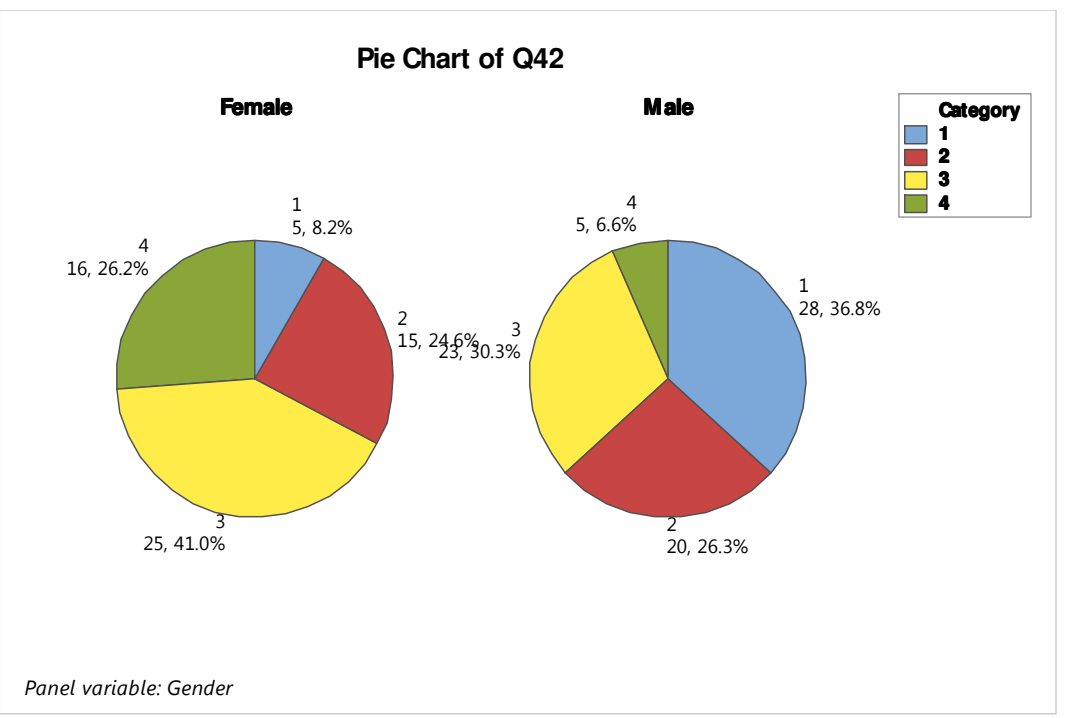

Figure 15- Girls are better readers than boys

(1-Strongly Disagree 2- Disagree 3-Agree 4- Strongly Agree)

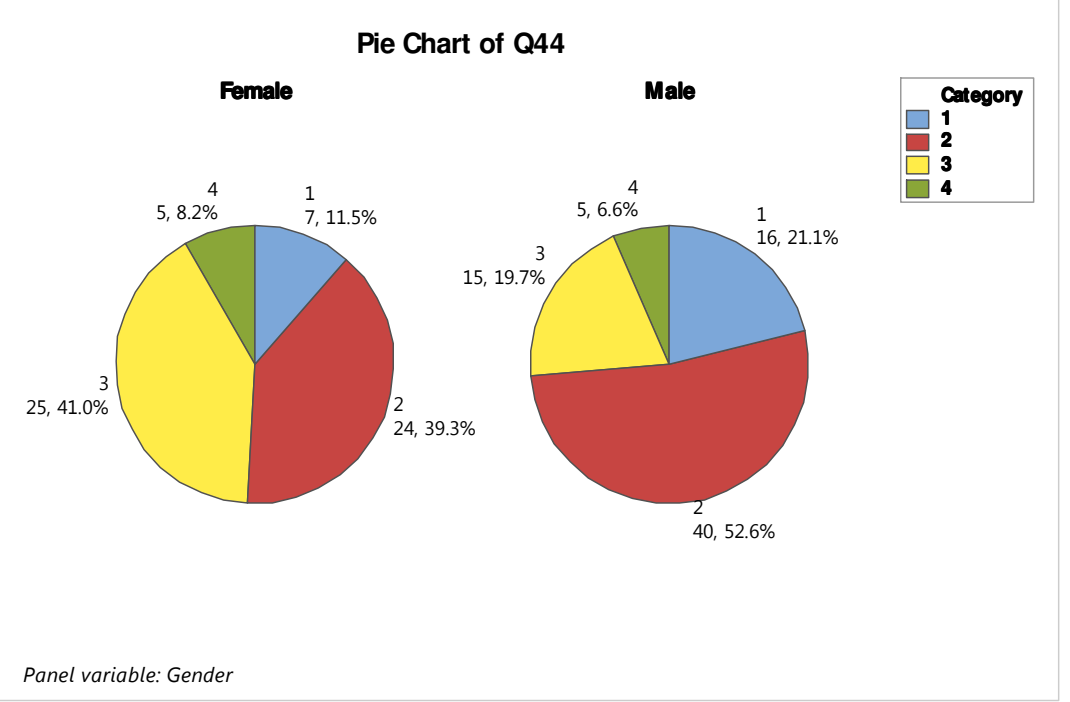

Figure 16- Most of the books for my age are written for girls

(1- Strongly Disagree 2- Disagree 3-Agree 4- Strongly Agree) 
Finally, boys significantly agreed over girls that they can read as well as girls which was somewhat unexpected given the studies on many boys' lack of self-efficacy in reading (Fig. 17) (McDowell et al., 2011; Smith \& Wilhelm, 2004).

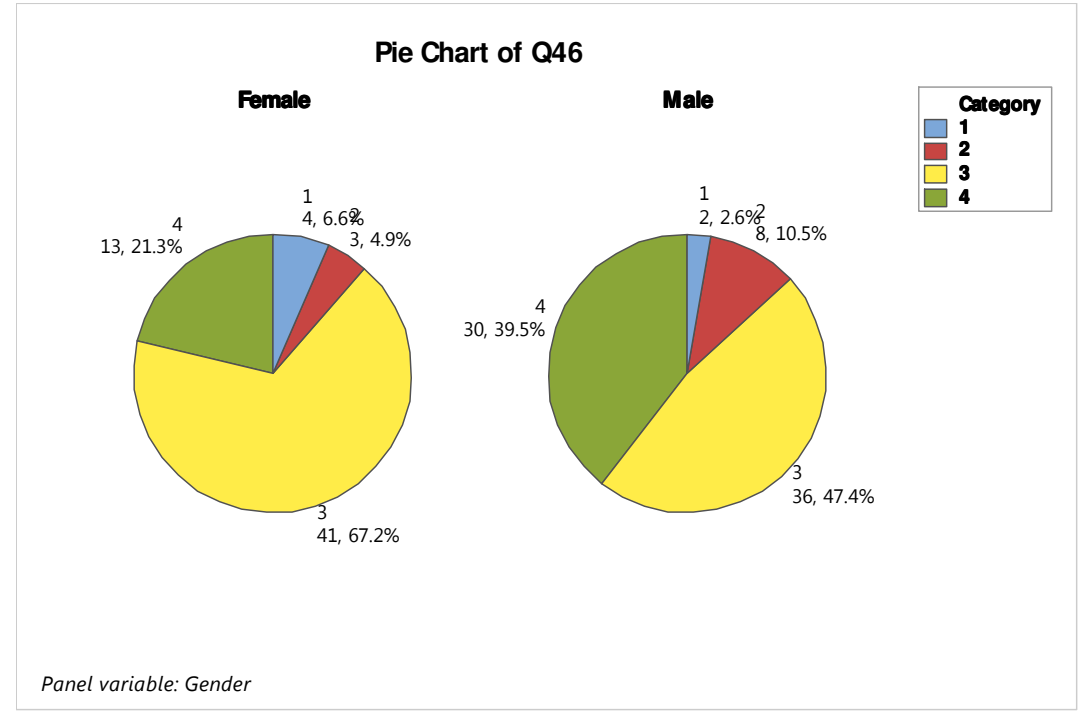

Figure 17- Boys can read as well as girls

\section{(1- Strongly Disagree 2- Disagree 3- Agree 4- Strongly Agree)}

For questions addressing interest and self-efficacy, all students disagreed that not liking to read, the difficulty of finding something interesting, believing they wouldn't understand a book, or that reading was too difficult or unimportant would be obstacles to reading, and there were no significant differences (Clark, 2010; McDowell et al., 2011; Smith \& Wilhelm, 2004). Females, however, indicated with a significant difference that they had more trouble finding time to read than boys, an idea which did not specifically appear in the literature (Fig. 18). 


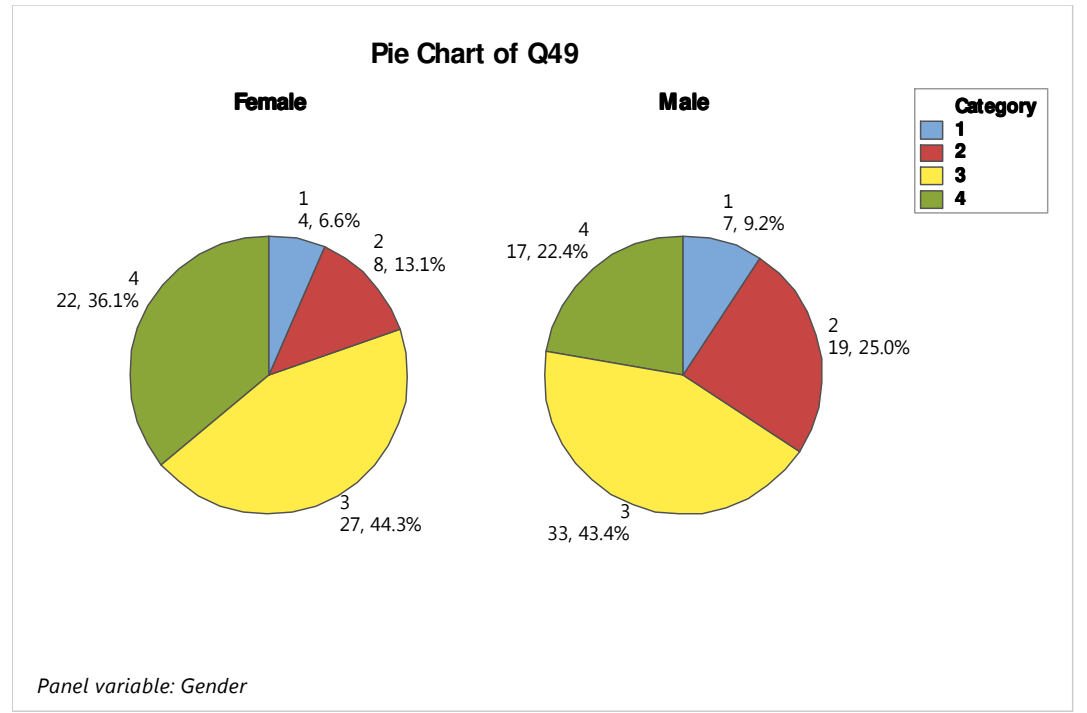

Figure 18- I don't read for fun more often because I don't have time (1- Strongly Disagree 2- Disagree 3-Agree 4- Strongly Agree)

Further in self-efficacy, there was no significant difference in boys' or girls' belief in their reading ability or the wish to read better, although surprisingly the Mean for boys' confidence in their reading ability was higher than girls' (Clark, 2010; McDowell et al., 2011; Smith \& Wilhelm, 2004).

In keeping with the literature's findings, boys indicated a significantly greater desire to read if they had questions they wanted to find answers for (Fig. 19) (Fisher \& Frey, 2012; Gillespie, 2010; Graham et al., 2008; Hughes-Hassell \& Rodge, 2007; Werderich, 2010). 


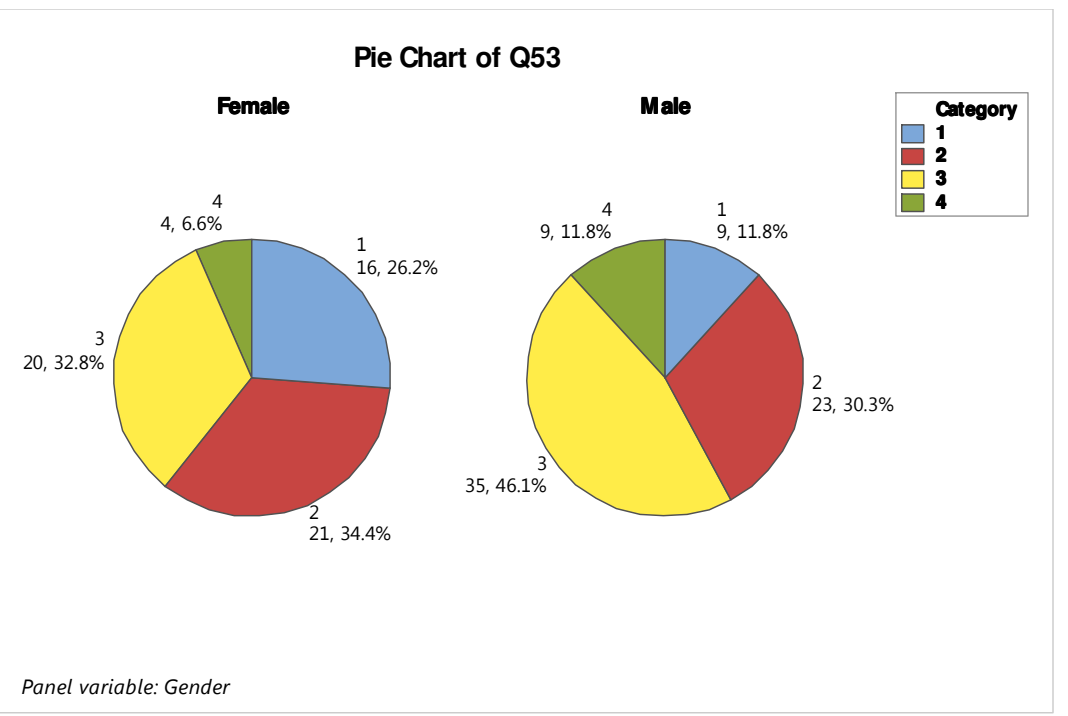

Figure 19- I would be more likely to read a book for fun if I had interesting questions I wanted to find answers for (1- Strongly Disagree $\quad 2$ - Disagree $\quad 3$ - Agree $\quad 4$ - Strongly Agree)

To address the idea that male role models would entice boys to read, both groups primarily disagreed that that would have a positive effect, and no significant difference was found (Canadian Council on Learning, 2009; Henry et al., 2012; Sokal, 2010; Werderich, 2010). In seeing whether a technological format would encourage reading, both groups denied interest in audiobooks, but boys were significantly more open to them (Fig. 20). Neither group indicated that any sort of e-reader such as a Kindle would encourage reading and no significant difference was found (Sokal, 2010; Witte, 2007). 


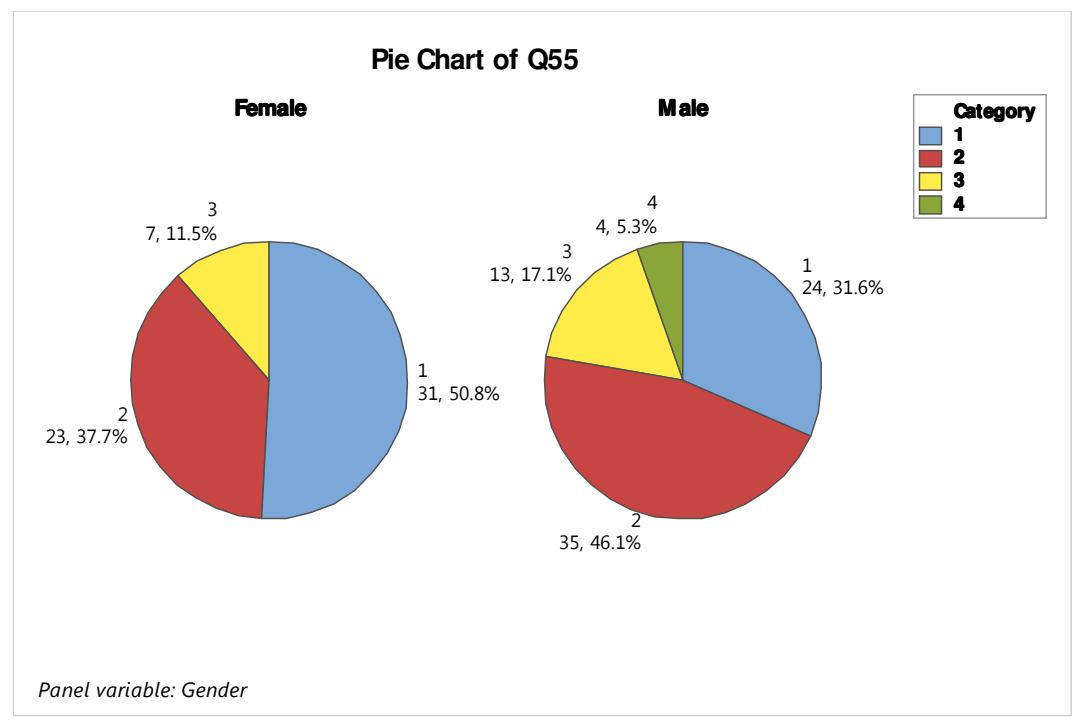

Figure 20- I would read more for fun if I could use audiobooks (1- Strongly Disagree 2- Disagree 3-Agree 4- Strongly Agree)

Finally, there were no significant differences between genders for whether the students read less, the same, or more for fun than they did two years ago (Fisher \& Frey, 2012).

Most of the students at our school have spent the majority of their academic years there. No significant differences were found in any categories for students who have attended at least one year of public school or who have been homeschooled for at least one year. In addition, none of the literature addressed any difference among school settings within the same study.

\section{Race}

Since a significant portion of the literature focused on African Americans, several questions were examined from that perspective, specifically with males against females and all other races, although the sample was small with just males $(N=11)$ and with all African Americans $(N=14)$. 
While there were no significant differences for any categories, several of the Mean numbers were interesting. The Mean for African American males was the highest of all races when asked if reading outside school was important, which fit with one study's idea that boys admire literate males and want to be better readers (Smith \& Wilhelm, 2004).

Although fiction preferences reflected results in the literature (Canadian Council on Learning, 2009; Canadian Council on Learning, 2009; Clark, 2010; Clark, 2010; Hughes-Hassell \& Rodge, 2007; Husband, 2012; Husband, 2012; Sokal, 2010), African Americans, specifically females, surprisingly had a higher Mean for nonfiction. African Americans, again mainly females, unexpectedly showed an affinity for graphic novels as well as websites or social media (Moeller, 2011; Sokal, 2010).

Looking at the idea of African Americans needing to see themselves in the text as well as the appeal of urban fiction/street lit (Elish-Piper \& Tatum, 2006; Kirkland, 2011; Moeller, 2011; Sokal, 2010), there were no significant results in questions asking whether students liked to read about characters with similar or different lifestyles than theirs.

A final set of questions was run with African Americans of both genders compared to all other races, although this only increased the sample size to $N=14$. These questions dealt with the transmission of cultural capital (Harris \& Graves Jr., 2010). There was no significance to any category. However, African Americans had the second-highest Mean when asked if their parents read to them frequently when they were young. Their Mean was one of the lowest when asked if they saw their parents read in their spare time. They were again high when asked if their siblings and other influential people in their lives read in their spare time. A larger sample size could provide more confirmation of these tendencies. 


\section{Open-ended Results}

Fifty-one students left comments in the open-ended section at the end. Approximately thirty-two of the responses were useful within this study. The other nineteen answers were a variation of "No" or "I'm bored." The remaining eighty-six students did not respond.

As done in other studies (Crumpton \& Gregory, 2011), these responses were not coded as part of the quantitative analysis. Either the response did not fit a quantitative category, which was the reason an open-ended option was provided to attract comments the researcher hadn't addressed, or the response simply reinforced what the student had already answered quantitatively.

Several themes emerged, although they were mixed by gender and race. Both males and females responded that choice was important, a strong idea found in the literature (Boone et al., 2010; Fisher \& Frey, 2012; Fredrick, 2006; Guerra, 2012; Sokal, 2010; Werderich, 2010).

Students wanted more relevance to real life stories and current events so they could apply the stories to their lives (Husband, 2012; Kirkland, 2011). Males complained that the books in school were "old timers"" books and "classic novels" such as To Kill a Mockingbird that should be updated to more modern, teenage action books such as the Goosebumps series (Scholes, 2010). Several more females than males, however, indicated they also like books that are connected to movies, a distinction which did not appear specifically in the literature but could relate to adolescents wanting literature that is relevant to their lives (Haddix, 2009; Husband, 2012).

Males and females both expressed a preference for mythology and fantasy which was surprising as not many females list fantasy as a preferred genre (Canadian Council on Learning, 2009; Clark, 2010; Husband, 2012; Sells, 2009; Werderich, 2010). 
Students were split on the idea of electronic readers although several recommended an app called Wattpad which has many standard works for free but also allows users to add their own stories and interact with one another (Sokal, 2010).

Two direct quotes reinforce the published literature's findings in terms of self-efficacy and motivation (McDowell et al., 2011; Sells, 2009; Smith \& Wilhelm, 2004).

"I LOVE reading. im just not good at it, and I need to find a book insrtesting." African American male

"i hate my life! i wish i could read but then again i hate reading." Caucasian male Finally, accompanied by numerous exclamation points, males and females equally expressed their love of reading.

I have always imagined paradise will be a kind of library. - Jorge Luis Borges 


\section{Chapter five}

\section{Discussion}

“There are multiple tangible and intangible influences on adolescent literacy development. In-school factors and out-of-school factors function in concert with students' external and internal resources, and they all combine to impact their literacy development" (Tatum, 2008).

As one can see, multiple studies over decades of research have not produced a definitive answer to increasing adolescents' literacy. This study did not expect to find the panacea either, but will add to the body of literacy literature, perhaps bolster the emergence of any large-scale trends, and particular aspects will be beneficial to local educators working with their unique student populations. Obviously, there is not a definitive answer for increasing adolescent male literacy because there is not one clear cause. One cannot identify an anti-literacy virus and vaccinate against it with one shot. Engaging with literature involves a host of threads woven through a child's life. As those threads separate, fray, or snap, the work of keeping kids involved in reading becomes more difficult, and we then see various studies crop up, each one pointing out one or several of the threads that is missing in that particular group. As with all things in life, since the biblical Fall, we're simply trying to reassemble all the broken parts of what once was whole so that it functions as it was meant to (Acts 3:19-21; Micah 4:6-7, NSRV).

However, taking the literature and data together, one can identify several components of the literacy solution that cross ethnic, SES, and gender lines.

First, from a Christian perspective, this researcher believes God established the family as the bedrock unit of society (Grudem, 1999). Fathers and mothers are given biblical mandates to train and raise their children in certain ways (Eph. 6:4; Deut. 6:6-9, NRSV). It comes as no 
surprise that parental involvement and encouragement can overcome many academic or environmental factors (Bowen et al., 2012). Strategies such as reading to children at a young age, modeling reading at home, helping your child find literature of high interest to them, and setting high expectations for academic achievement all contribute to increased literacy (Bowen et al., 2012; Elish-Piper \& Tatum, 2006; Lutz, 1986). However, the likelihood of every broken family suddenly reuniting into a cohesive unit is slim, so how do we deal with reality?

The teacher should design creative and engaging lessons (Banks, 2011; Kirkland, 2011). One teacher taught Beowulf in a straightforward lecture, worksheet, and unit test format. The students were bored. He taught the next lesson on The Iliad using connections to pop culture and invited students to produce comic book style versions of The Iliad adapted to their urban lifestyle. The students enthusiastically discussed the themes of the book and were successful (Kirkland, 2011).

In addition, the teacher herself should be enthusiastic and model the thinking and writing that goes along with understanding the life lessons in a book (Banks, 2011). A teacher also needs to support the learners and be a leader but also a fellow learner (Fisher \& Frey, 2012). Top students are often self-motivated (Fredrick, 2006), but the majority of learners require work on the teacher's part in the form of modeling, scaffolding, and feedback to get them to take up productive leisure reading independently (Banks, 2011; Boone et al., 2010; Elish-Piper \& Tatum, 2006; Fisher \& Frey, 2012; Hughes-Hassell, 2012; Werderich, 2010; Witte, 2007). They will respond but need a hand to cross that bridge. Meaningful follow-up activities that engage students in writing or discussing the themes of a book will increase interest and comprehension. These activities include literature discussion circles, blogs, and teacher dialogue journals (Fredrick, 2006; Werderich, 2010; Witte, 2007). 
Next, educators should expand their definition of what constitutes acceptable literature and let boys start with nearly anything that grabs them (Allyn, 2011; Canadian Council on Learning, 2009; Hughes-Hassell \& Rodge, 2007; Sadowski, 2010). “A good book for a boy is one he wants to read" James Maloney (Henry et al., 2012).

Finally, the intrinsic motivation to read is critical (Clark, 2010; Gillespie, 2010; Henry et al., 2012). Adolescent boys need a reason to open a book (Elish-Piper \& Tatum, 2006). They won't, as many girls do, just pick something off the shelf and get lost in its pages or muddle through an assigned book despite nominal interest (Canadian Council on Learning, 2009). This researcher highly recommends using "essential questions" prior to a novel to give students something to look for and discuss (Fisher \& Frey, 2012).

Motivating reasons for adolescent boys to read include feeling competent, a desire for inquiry, immediate life application, seeing themselves in the text, having appealing genres, choice of text, and teacher support (Allyn, 2011; Boone et al., 2010; Fisher \& Frey, 2012; Fredrick, 2006; Guerra, 2012; Hughes-Hassell \& Rodge, 2007; Moeller, 2011; Smith \& Wilhelm, 2004; Sokal, 2010; Werderich, 2010).

Ideally, every student would have an individually tailored reading curriculum. Books would be at the perfect reading level, key in on a student's precise interests, and there would be meaningful application to real life. That's really what every endeavor is trying to meet-the individual. However, practicality doesn't allow it. Instead, we find the balance between independent reading and whole class novels, male and female themes and protagonists, fiction and nonfiction, and the rest. Almost any literature can engage students if presented the right way and will give them a platform to strike out on their own. 


\section{Suggestions for Further Study}

One problem with the survey was students either thinking of additional facets to a question and therefore having trouble answering definitively or simply misinterpreting a question.

Misinterpretation, for instance, involved the demographic section, where several students misunderstood "Multi-ethnic" to mean their European heritage, e.g., Italian and Swiss, whereas that should just be marked Caucasian. A few students did not know that Caucasian meant white.

For the questions about attending public school or being homeschooled for at least a year, several students asked which years were applicable, i.e., did preschool count? This researcher told them kindergarten and above since that is when reading becomes relevant, but perhaps the baseline should have been as high as first grade. In addition, for "Magazines count as legitimate reading", students remarked it depended what kind of magazine, e.g., National Geographic or a tabloid.

This researcher should have asked a question to establish a baseline on reading frequency (Hughes-Hassell \& Rodge, 2007), for instance, "I read at least three books a year for fun." Since the researcher is trying to encourage reluctant readers to become lifelong readers, the barriers to reading for them may be different than for frequent readers as would the motivation to start reading (Sokal, 2010). When asking a question such as "The following are important to me when choosing something to read:", or "I don't read for fun more often because", this researcher is more interested in the responses of reluctant readers. However, since a belief of this study is that books aren't the only legitimate means of leisure reading (Allyn, 2011; Hughes-Hassell \& Rodge, 2007; Sadowski, 2010), a baseline question would either give a false representation of reading frequency since a student may read a great deal just not books, or the researcher would 
have to create a detailed question with multiple categories that may not integrate as well in sorting the final data.

For questions 12-22, which determined motivation to read, the researcher should have added a category for "wanted to learn something" or "seemed to have answers for my questions" to address the motivation of inquiry (Fisher \& Frey, 2012).

The survey should have had a question such as, "I can get interested in any book if the teacher makes it fun" to address the findings that the teacher plays a significant role in encouraging literacy (Banks, 2011; Bowen et al., 2012; Sokal, 2010; Werderich, 2010). The survey should have contained a question such as "I enjoy reading" (Hughes-Hassell \& Rodge, 2007).

The survey also should have included a question dealing with peer pressure or the perception that reading is for nerds (Moeller, 2011; Scholes, 2010). For instance, "My friends would make fun of me if they knew I liked to read." This researcher would be particularly interested in the gender breakdown of that response.

Next, the survey perhaps should have included a more direct question about parental involvement such as "My parents have communicated to me how important reading is" (Harris \& Graves Jr., 2010).

One surprising result was that boys did not respond to technology to access literature. Website recommendations and e-readers were not enticing. If the published literature has suggested that technology is a path for boys to increase literacy, one should ask what form then does that take? A future study could seek ways that technology can reach boys for literacy or be used to discard the whole theory. 
A significant result of the study was that girls reported having more difficulty finding time to read. Yet they score higher in literacy and still manage to have more and varied reading experiences. A future study may look at organization, time management, or prioritization between genders. This researcher believes the interest factor may again play a part as girls perhaps make time for the activity of reading which they enjoy more.

Finally, the survey should have included the ninth graders in the school to increase the sample and to see if reading attitudes or practices change with the transition to high school (Henry et al., 2012).

While the gender balance was sufficient $($ Males $=76$, Females $=61)$, the racial difference was small. Further studies should sample at least one urban school and one suburban public school. 


\section{References}

Allyn, P. (2011). Against the whole-class novel. Education Week, 30(22), 27-29.

Banks, E. (2011). A passion for fiction. NATE Classroom, (15), 34-36.

Boone, J., Rawson, C., \& Vance, K. (2010). Getting it right: Building a bridge to literacy for adolescent african-american males. School Library Monthly, 27(2), 34-37.

Bowen, G. L., Hopson, L. M., Rose, R. A., \& Glennie, E. J. (2012). Students' perceived parental school behavior expectations and their academic performance: A longitudinal analysis. Family Relations: An Interdisciplinary Journal of Applied Family Studies, 61(2), 175-191.

Bozack, A. (2011). Reading between the lines: Motives, beliefs, and achievement in adolescent boys. High School Journal, 94(2), 58-76.

Brozo, W. G. (2012). Building bridges for boys: Graphic novels in the content classroom. Journal of Adolescent \& Adult Literacy, 55(6), 550-550. doi:10.1002/JAAL.00064

Canadian Council on Learning. (2009). Lessons in learning: Why boys don't like to read--gender differences in reading achievement. . Canadian Council on Learning,

Clark, C. (2010). Boys versus girls: Why is the gender gap in reading widening? Literacy Today, (64), 28.

Crumpton, H., \& Gregory, A. (2011). "I'm not learning": The role of academic relevancy for low-achieving students. The Journal of Educational Research, 104, 42-53. doi:10.1080/00220670903567398 
Elish-Piper, L., \& Tatum, A. W. (2006). Addressing the literacy needs of adolescent students: Listening to their voices. New England Reading Association Journal, 42(1), 6-12.

Fisher, D., \& Frey, N. (2012). Motivating boys to read: Inquiry, modeling, and choice matter. Journal of Adolescent \& Adult Literacy, 55(7), 587-596. doi:10.1002/JAAL.00070

Fredrick, T. (2006). Choosing to belong: increasing adolescent male engagement in the ELA classroom. Changing English, 13(1), 151-159. doi:10.1080/13586840500523596

Frochtwajg, J. (2009). Paper boys. Bitch Magazine: Feminist Response to Pop Culture, (45), 1111.

Fryer, R. (2006). Acting white. Education Next, 6(1), July 19, 2014.

Gillespie, J., Hélène. (2010). Boys and girls: Differences in the influence of interest on reading comprehension. Literacy Today, (63), 31.

Graham, J., Tisher, R., Ainley, M., \& Kennedy, G. (2008). Staying with the text: the contribution of gender, achievement orientations, and interest to students' performance on a literary task. Educational Psychology, 28(7), 757-776. doi:10.1080/01443410802260988

Grudem, W. (1999). Redemption in christ reaffirms the creation order. Bible doctrine: essential teachings of the christian faith (pp. 205-206). Grand Rapids, Michigan: Zondervan.

Guerra, S. F. (2012). Using urban fiction to engage at-risk and incarcerated youths in literacy instruction. Journal of Adolescent \& Adult Literacy, 55(5), 385-394.

doi:10.1002/JAAL.00047 
Haddix, M. (2009). Black boys can write: Challenging dominant framings of african american adolescent males in literacy research International Reading Association.

Harris, T. S., \& Graves Jr., S. L. (2010). The influence of cultural capital transmission on reading achievement in african american fifth grade boys. Journal of Negro Education, 79(4), 447457.

Henry, K., Lagos, A., \& Berndt, F. (2012). Bridging the literacy gap between boys and girls: An opportunity for the national year of reading 2012. Australian Library Journal, 61(2), 143150.

Hughes-Hassell, S., Koehler, E., \& Barkley, H. A. (2010). Supporting the literacy needs of african american transitional readers. Teacher Librarian, 37(5), 18-23.

Hughes-Hassell, S., \& Rodge, P. (2007). The leisure reading habits of urban adolescents. Journal of Adolescent \& Adult Literacy, (1), 22. doi:10.2307/40015543

Hughes-Hassell, S. (2012). Librarians form a bridge of books to advance literacy. Phi Delta Kappan, 93(5), 17.

Husband, T. (2012). Why can't jamal read? Phi Delta Kappa International.

Johnson, B., \& Christensen, L. (2008a). Determining the sample size when random sampling is used. Educational research: Quantitative, qualitative, and mixed approaches (3rd ed., pp. 241-243). Los Angeles: Sage Publications. 
Johnson, B., \& Christensen, L. (2008b). The research continuum. Educational research: Quantitative, qualitative, and mixed approaches (3rd ed., pp. 445-452). Los Angeles: Sage Publications.

Kirkland, D. E. (2011). Books like clothes: Engaging young black men with reading. Journal of Adolescent \& Adult Literacy, 55(3), 199-208. doi:10.1002/JAAL.00025

Koren, J. (September 13, 2008). What is young adult literature? Retrieved, July 19, 2014, Retrieved from http://www.slideshare.net/joh5700/what-is-young-adult-literaturepresentation

Lutz, E. (1986). Parental involvement in the secondary reading program: ERIC/RCS. Journal of Reading, 29, 456-458.

McDowell, K. D., Sweeney, R., \& Ziolkowski, R. A. (2011). Adolescent readers: Relatedness of ability and attitudes. Global Education Journal, (1), 80-90.

Moeller, R. A. (2011). 'Aren't these boy books?': High school students' readings of gender in graphic novels. Journal of Adolescent \& Adult Literacy, (7), 476. doi:10.2307/41203397

Richter, J. (2006). Literature-N-living: Inspiring youthful offenders to embrace learning. Corrections Today, 68(7), 30.

Sadowski, M. (2010). Putting the 'Boy crisis' in context. Education Digest, 76(3), 10-13.

Scholes, L. (2010). Boys, masculinity and reading: Deconstructing the homogenizing of boys in primary school literacy classrooms. International Journal of Learning, 17(6), 437-450. 
Sells, J. (2009). Playing the literacy game. Literacy Today, (59), 17.

Smith, M., \& Wilhelm, J. D. (2004). "I just like being good at it": The importance of competence in the literate lives of young men. Journal of Adolescent \& Adult Literacy, 47(6), 454-461.

Sokal, L. (2010). Long-term effects of male reading tutors, choice of text and computer-based text on boys? reading achievement. Language \& Literacy: A Canadian Educational EJournal, 12(1), 116-127.

Tatum, A. W. (2003). All "degreed" up and nowhere to go: Black males and literacy education. Journal of Adolescent \& Adult Literacy, 46(8), 620-623.

Tatum, A. W. (2006). Engaging african american males in reading. Educational Leadership, 63(5), 44-49.

Tatum, A. W. (2008). Toward a more anatomically complete model of literacy instruction: A focus on african american male adolescents and texts. Harvard Educational Review, 78(1), $155-180$.

Tatum, A. W., \& Muhammad, G. E. (2012). African american males and literacy development in contexts that are characteristically urban. Urban Education, 47(2), 434-463.

Watson, A., Kehler, M., \& Martino, W. (2010). The problem of boys' literacy underachievement: Raising some questions. Journal of Adolescent \& Adult Literacy, (5), 356. doi: $10.2307 / 25614569$ 
Werderich, D. E. (2010). RESPONDING TO BOY READERS A closer look at the role of the teacher in dialogue journals. Middle Grades Research Journal, 5(2), 91-106.

Wheldall, K., \& Watkins, R. (2004). Literacy levels of male juvenile justice detainees. Educational Review, 56(1), 3-11. doi:10.1080/0013191032000152237

Williams, B. T. (2006). Girl power in a digital world: Considering the complexity of gender, literacy, and technology. Journal of Adolescent \& Adult Literacy, 50(4), 300-307. doi:10.1598/JAAL.50.4.6

Witte, S. (2007). 'That's online writing, not boring school writing': Writing with blogs and the talkback project. Journal of Adolescent \& Adult Literacy, (2), 92. doi:10.2307/40021839 


\section{Appendix A}

\section{Survey}

All questions were on a four-point Likert scale of Strongly Disagree (1), Disagree (2), Agree (3), or Strongly Agree (4). Original survey question numbers are given first then the statistical number from the data that correlates to it, e.g. Q56.

1. (Q1) Reading on your own outside of school is important.

2. (Q2) I would read more for fun if I had more time.

3. For fun, I prefer to read (please answer both)

fiction $(\mathrm{Q} 3)$

nonfiction $(\mathrm{Q} 4)$

4. For fun, I prefer to read

books (Q5)

magazines (Q6)

newspapers (Q7)

graphic novels or comic books (Q8)

websites or social media (Q9)

5. (Q10) I like to read about characters who have a similar lifestyle or history as I do.

6. (Q11) I like to read about characters who are completely different from me.

7. The following are important to me when choosing something to read:

The cover looks interesting (Q12)

The summary on the back sounds good (Q13)

A friend recommended it (Q14) 
A teacher/librarian recommended it (Q15)

A parent recommended it (Q16)

An adult friend recommended it (Q17)

I heard about it on social media (Q18)

8. I chose the last book I read for fun because

The cover looked interesting (Q19)

The summary on the back sounded good (Q20)

Someone I know recommended it $(\mathrm{Q} 21)$

I heard about it on social media (Q22)

9. I would be MORE likely to read a book if recommended by a(n)

friend $(\mathrm{Q} 23)$

teacher/librarian (Q24)

parent $(\mathrm{Q} 25)$

adult friend (Q26)

website or social media (Q27)

10. I would be LESS likely to read a book if recommended by a(n)

friend $(\mathrm{Q} 28)$

teacher/librarian (Q29)

parent $(\mathrm{Q} 30)$

adult friend (Q31)

website or social media (Q32)

11. (Q33) Influential people in my life believe reading for fun is important.

12. (Q34) My parents read to me frequently when I was young. 
13. (Q35) I see my parents read in their spare time.

14. (Q36) I see my siblings read in their spare time. (This question included an N/A option)

15. (Q37) I see influential people in my life read in their spare time.

16. (Q38) Magazines count as legitimate reading.

17. (Q39) Newspapers count as legitimate reading.

18. (Q40) Graphic novels or comic books count as legitimate reading.

19. (Q41) Internet surfing counts as legitimate reading.

20. (Q42) Girls are better readers than boys.

21. (Q43) Reading is more of a girl activity.

22. (Q44) Most of the books for my age are written for girls.

23. (Q45) Teachers mostly pick books that girls like.

24. (Q46) Boys can read as well as girls.

25. I don't read for fun more often because

I can't find anything that interests me (Q47)

I don't like to read (Q48)

I don't have time (Q49)

reading is difficult and takes too long (Q50)

reading isn't that important (Q51)

I don't believe I would be able to understand or finish the book (Q52)

26. (Q53) I would be more likely to read a book for fun if I had interesting questions I wanted to find answers for.

27. (Q54) If someone of the same gender recommended something good to read, I would be more likely to read it. 
28. Evaluate the following statements:

I would read more for fun if I could use audiobooks (Q55)

If I used an audiobook, I would also follow along in the paper book (Q56)

Listening to audiobooks WITHOUT following the paper book counts as reading (Q57)

29. (Q58) I would read more for fun if I could do it electronically like on my phone or using an e-reader such as a Kindle.

30. (Q59) I am confident in my reading ability.

31. (Q60) I wish I could read better.

32. (Q61) I read LESS for fun than I did two years ago.

33. (Q62) I read about the SAME amount for fun as I did two years ago.

34. (Q63) I read MORE for fun than I did two years ago.

35. Gender

36. Race
African American
American Indian
Asian
Caucasian
Hispanic
Multi-racial
Native Hawaiian or Pacific Islander

37. I have attended at least one year of public school in my life.

38. I have been homeschooled at least one year in my life.

39. Age 
40. (Open-ended) Is there anything else you would like to say about books, reading, this survey, or what it would take to get you to be a more frequent reader? 


\section{Appendix B}

\section{Tukey Pairwise Comparisons}

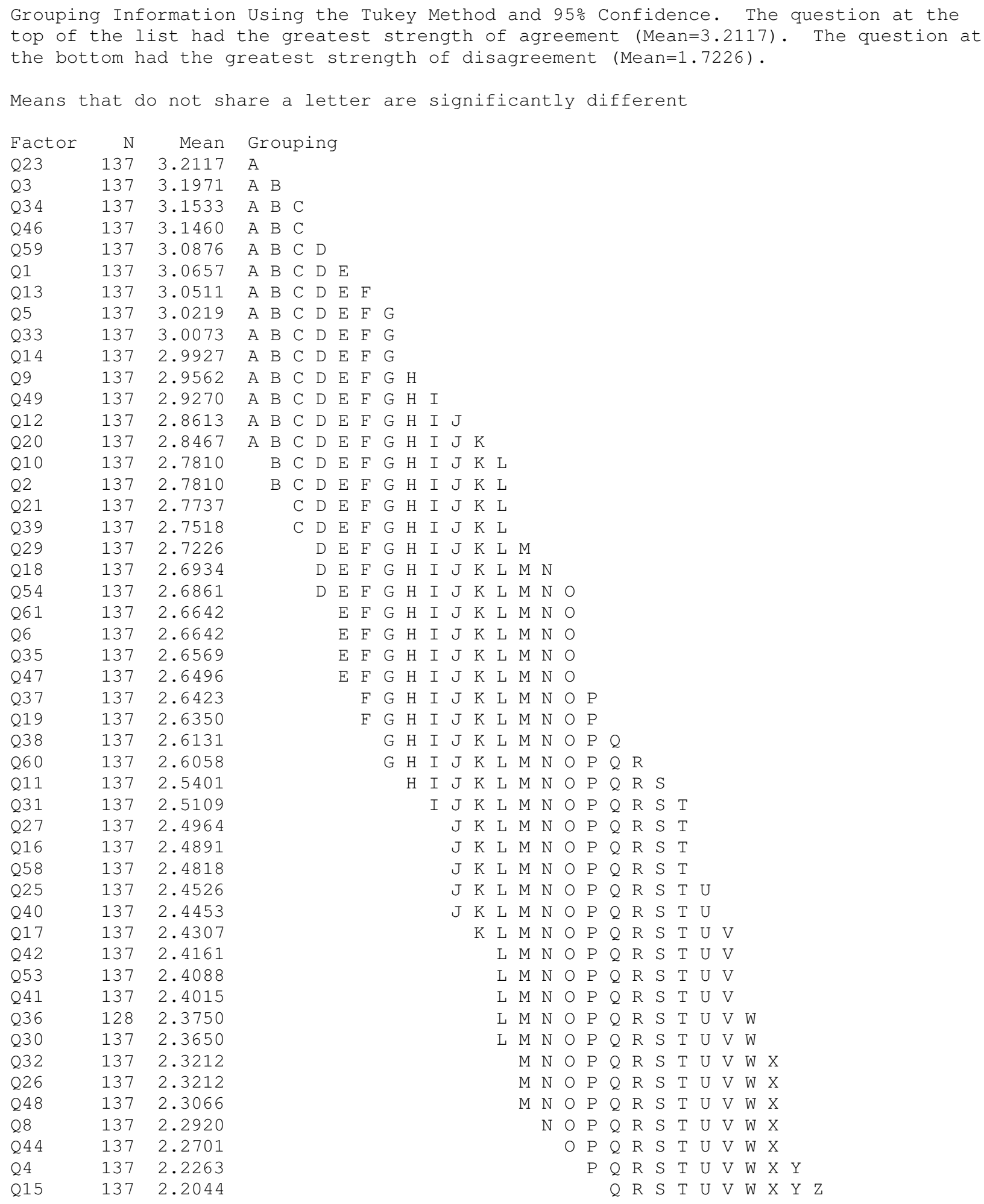




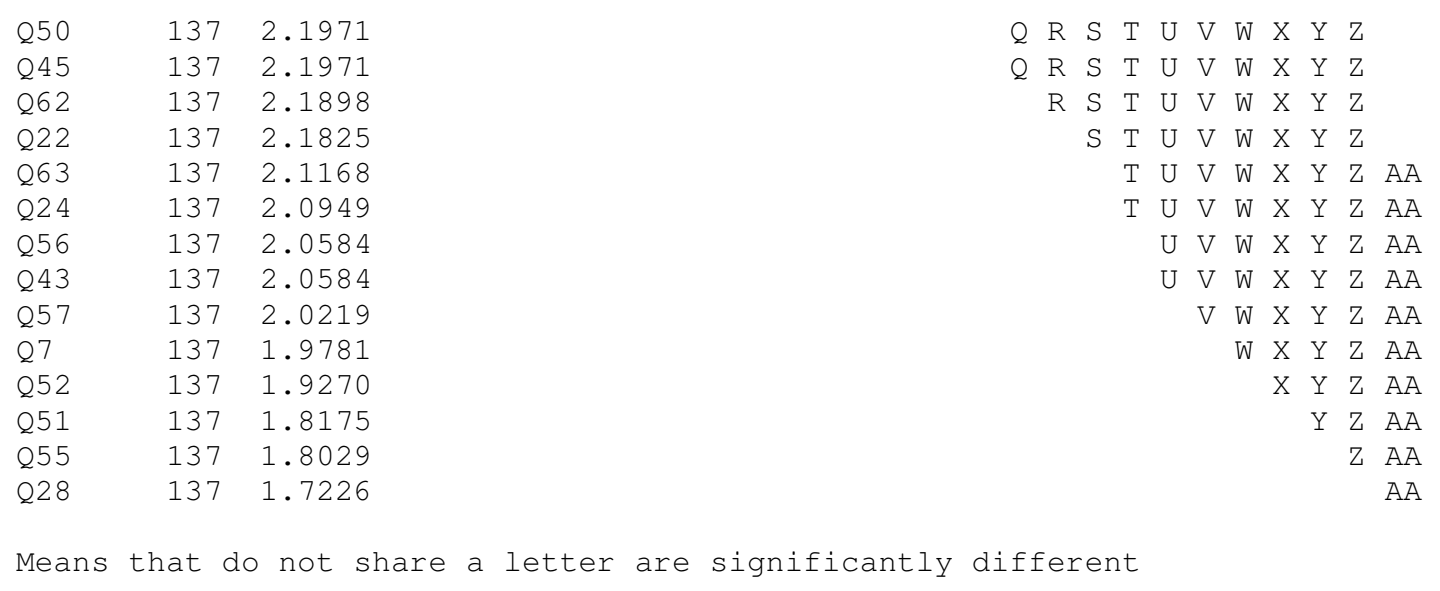




\section{Appendix C}

\section{General Linear Model: Q1, Q2, ... versus African American, Gender}

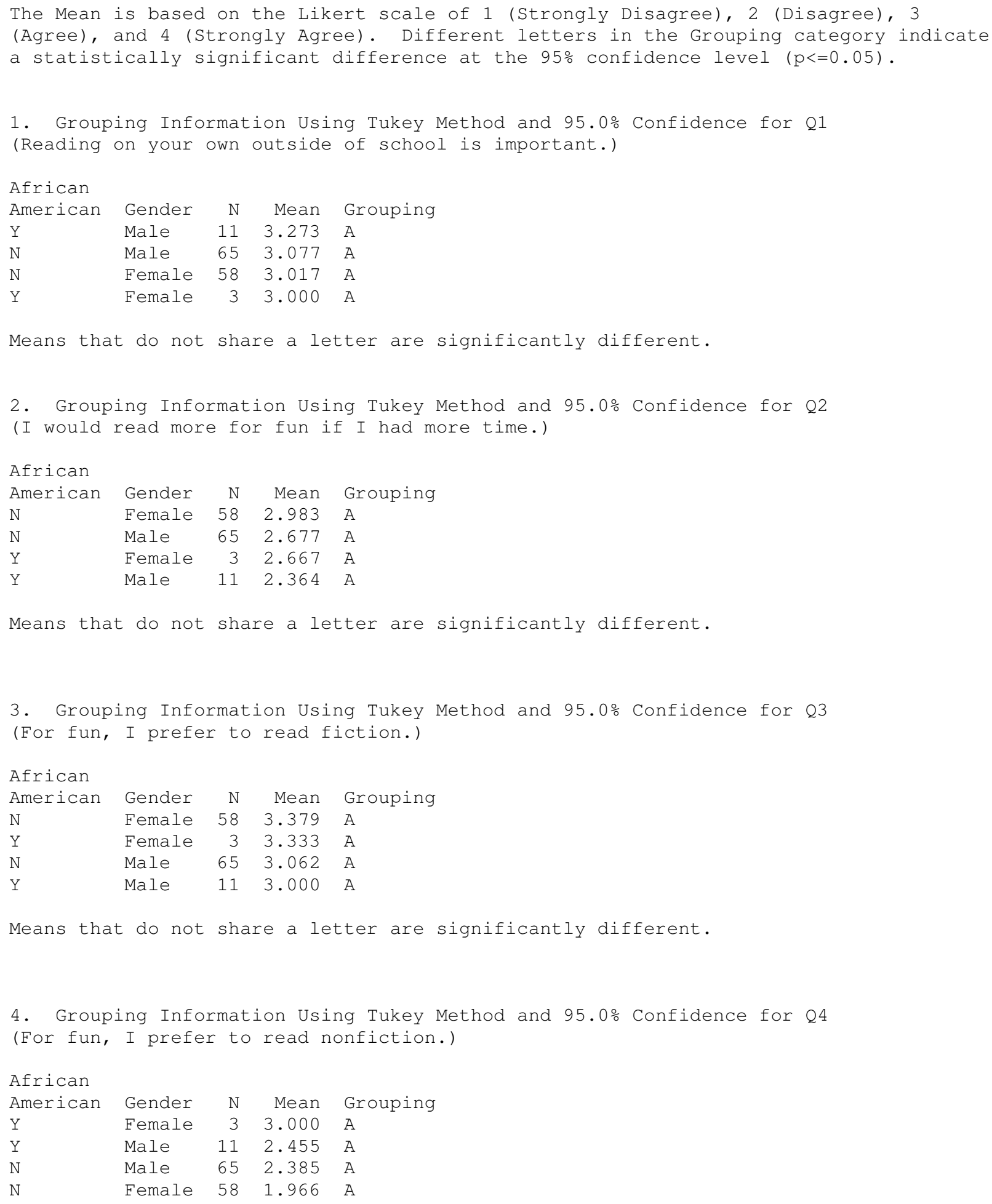




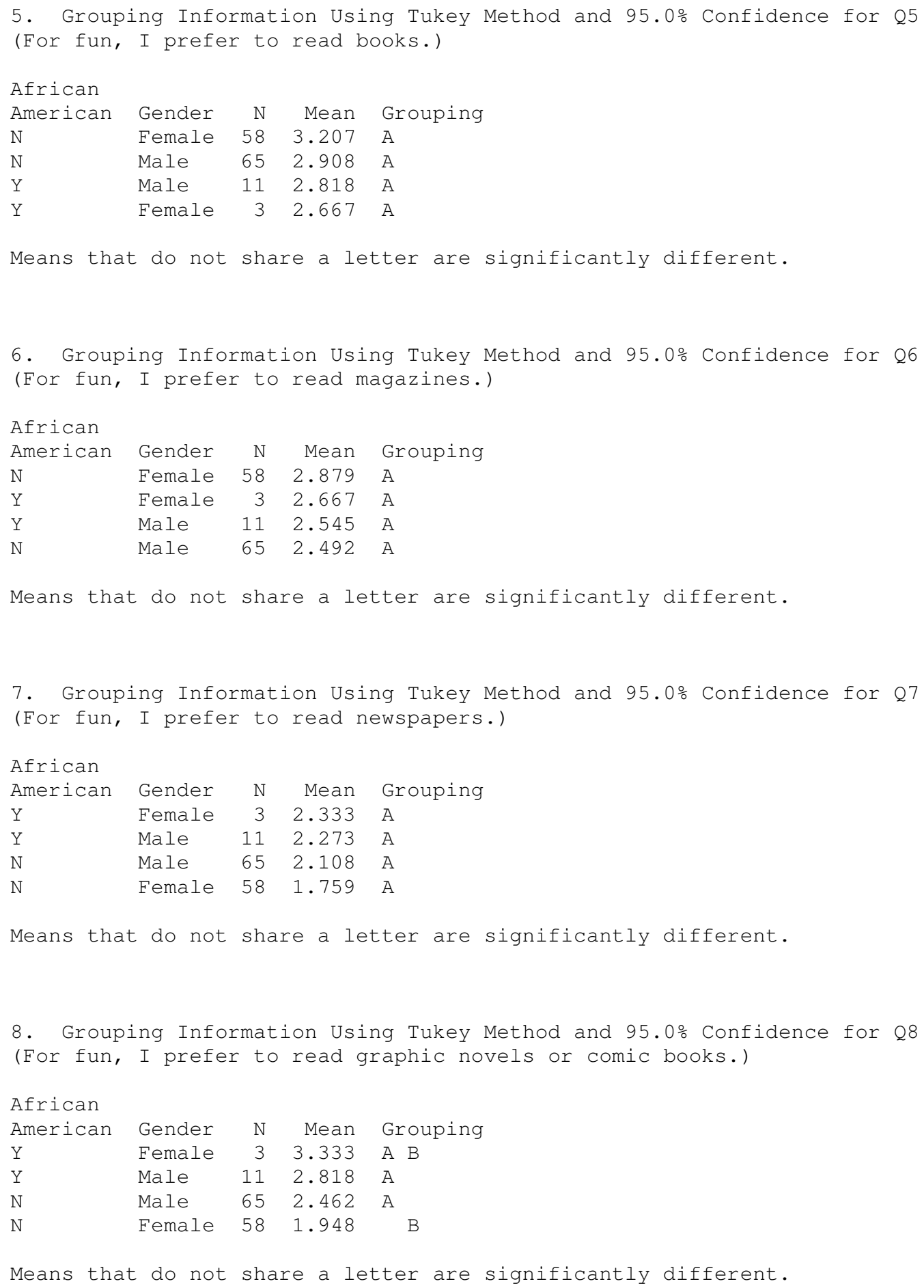


9. Grouping Information Using Tukey Method and 95.0\% Confidence for 29

(For fun, I prefer to read websites or social media.)

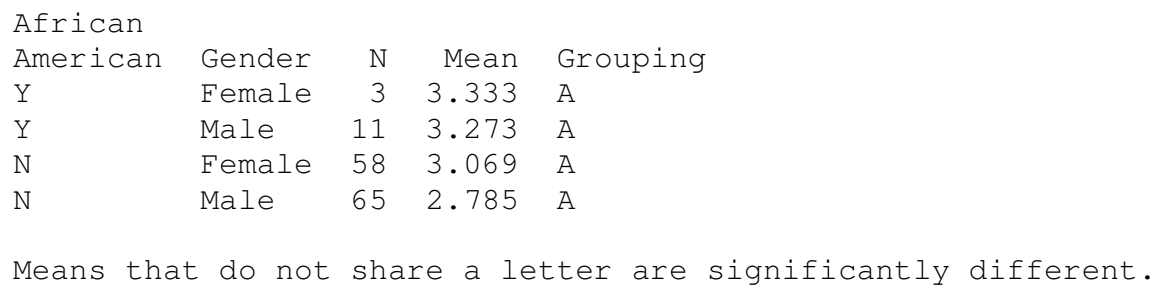

\section{General Linear Model: Q33, Q34, Q35, Q36, Q37 versus African American}

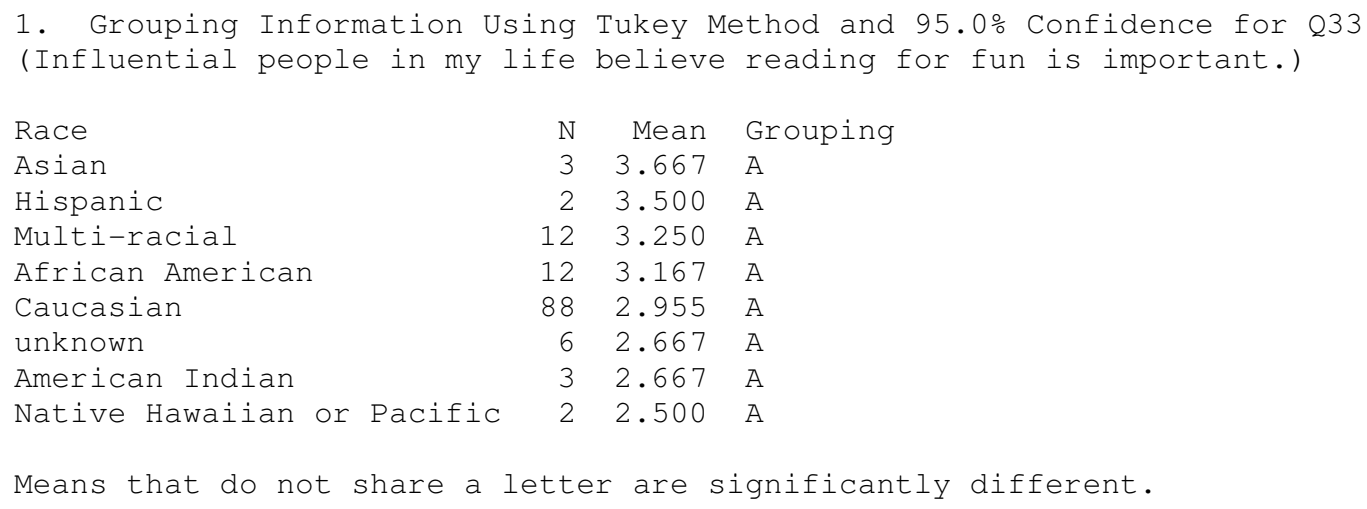


2. Grouping Information Using Tukey Method and 95.0\% Confidence for Q34 (My parents read to me frequently when I was young.)

$\begin{array}{lrrl}\text { Race } & \text { N } & \text { Mean } & \text { Grouping } \\ \text { Native Hawailan or Pacific } & 2 & 3.500 & \mathrm{~A} \\ \text { African American } & 2 & 3.417 & \mathrm{~A} \\ \text { unknown } & 6 & 3.333 & \mathrm{~A} \\ \text { Multi-racial } & 2 & 3.333 & \mathrm{~A} \\ \text { Asian } & 3 & 3.333 & \mathrm{~A} \\ \text { Caucasian } & 88 & 3.091 & \mathrm{~A} \\ \text { American Indian } & 3 & 3.000 & \mathrm{~A} \\ \text { Hispanic } & 2 & 2.500 & \mathrm{~A} \\ & & \end{array}$

3. Grouping Information Using Tukey Method and 95.0\% Confidence for 235 (I see my parents read in their spare time.)

$\begin{array}{lrrl}\text { Race } & \text { N } & \text { Mean } & \text { Grouping } \\ \text { Hispanic } & 2 & 4.000 & \mathrm{~A} \\ \text { Native Hawaitan or Pacific } & 2 & 3.000 & \mathrm{~A} \\ \text { Multi-racial } & 12 & 2.667 & \mathrm{~A} \\ \text { Asian } & 3 & 2.667 & \mathrm{~A} \\ \text { unknown } & 6 & 2.667 & \mathrm{~A} \\ \text { Caucasian } & 88 & 2.602 & \mathrm{~A} \\ \text { African American } & 12 & 2.417 & \mathrm{~A} \\ \text { American Indian } & 3 & 2.333 & \mathrm{~A}\end{array}$

Means that do not share a letter are significantly different.

4. Grouping Information Using Tukey Method and 95.0\% Confidence for Q36 ( I see my siblings read in their spare time.)

\begin{tabular}{|c|c|c|c|}
\hline Race & $\mathrm{N}$ & Mean & Grouping \\
\hline unknown & 6 & 2.833 & A \\
\hline African American & 12 & 2.667 & A \\
\hline Asian & 3 & 2.667 & A \\
\hline Hispanic & 2 & 2.500 & $\mathrm{~A}$ \\
\hline Caucasian & 88 & 2.352 & A \\
\hline Multi-racial & 12 & 2.167 & A \\
\hline American Indian & 3 & 2.000 & A \\
\hline Native Hawaiian or Pacific & 2 & 1.500 & A \\
\hline \multicolumn{4}{|c|}{ Means that do not share a letter are significant } \\
\hline \multicolumn{4}{|c|}{$\begin{array}{l}\text { 5. Grouping Information Using Tukey Method and } \\
\text { (I see influential people in my life read in the }\end{array}$} \\
\hline Race & $\mathrm{N}$ & Mean & Grouping \\
\hline Multi-racial & 12 & 3.000 & A \\
\hline African American & 12 & 2.667 & A \\
\hline Asian & 3 & 2.667 & A \\
\hline Caucasian & 88 & 2.602 & $\mathrm{~A}$ \\
\hline unknown & 6 & 2.500 & A \\
\hline Native Hawaiian or Pacific & 2 & 2.500 & A \\
\hline Hispanic & 2 & 2.000 & $\mathrm{~A}$ \\
\hline American Indian & 3 & 2.000 & A \\
\hline
\end{tabular}




\section{General Linear Model: Q1, Q2, ... versus Gender}

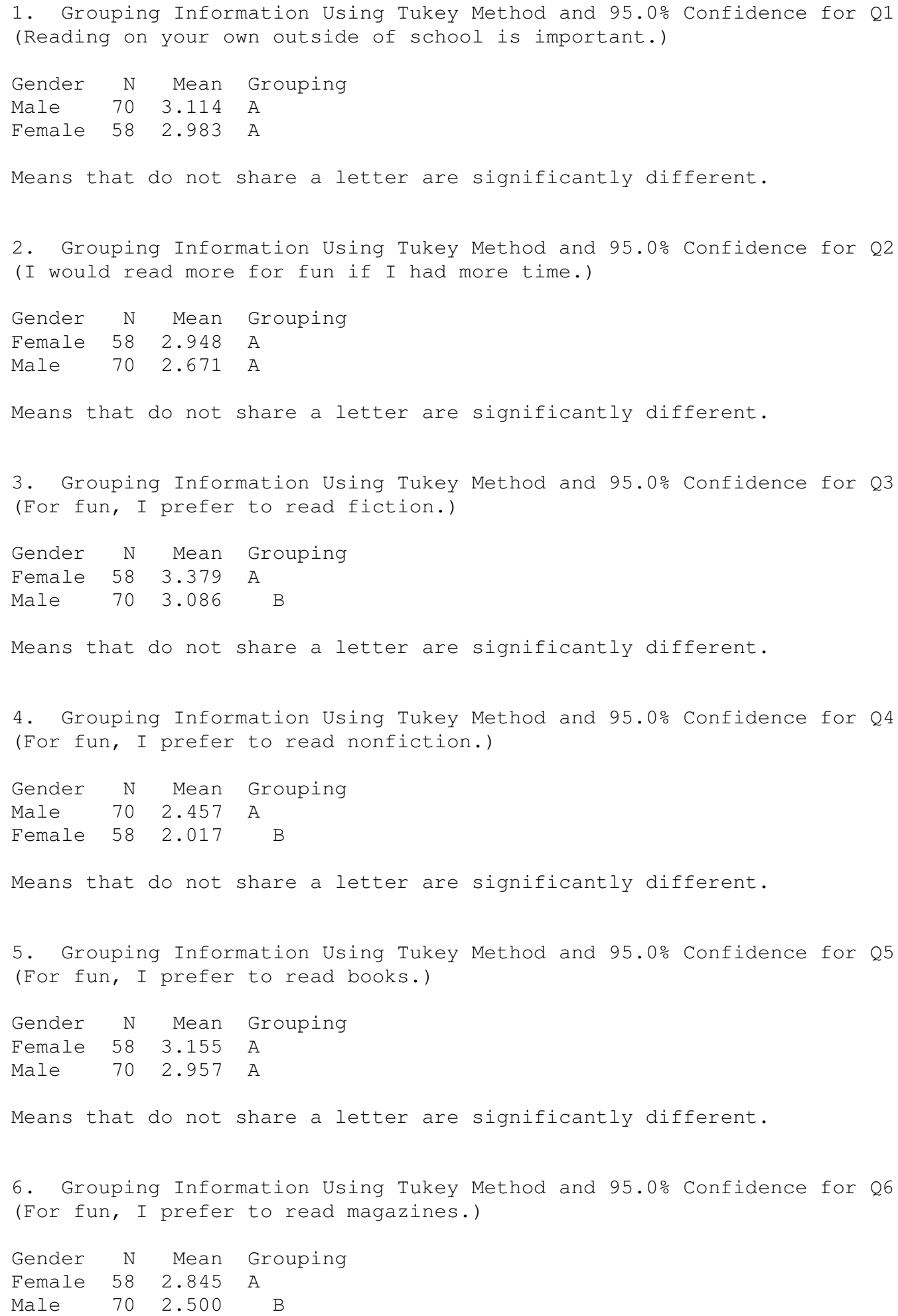




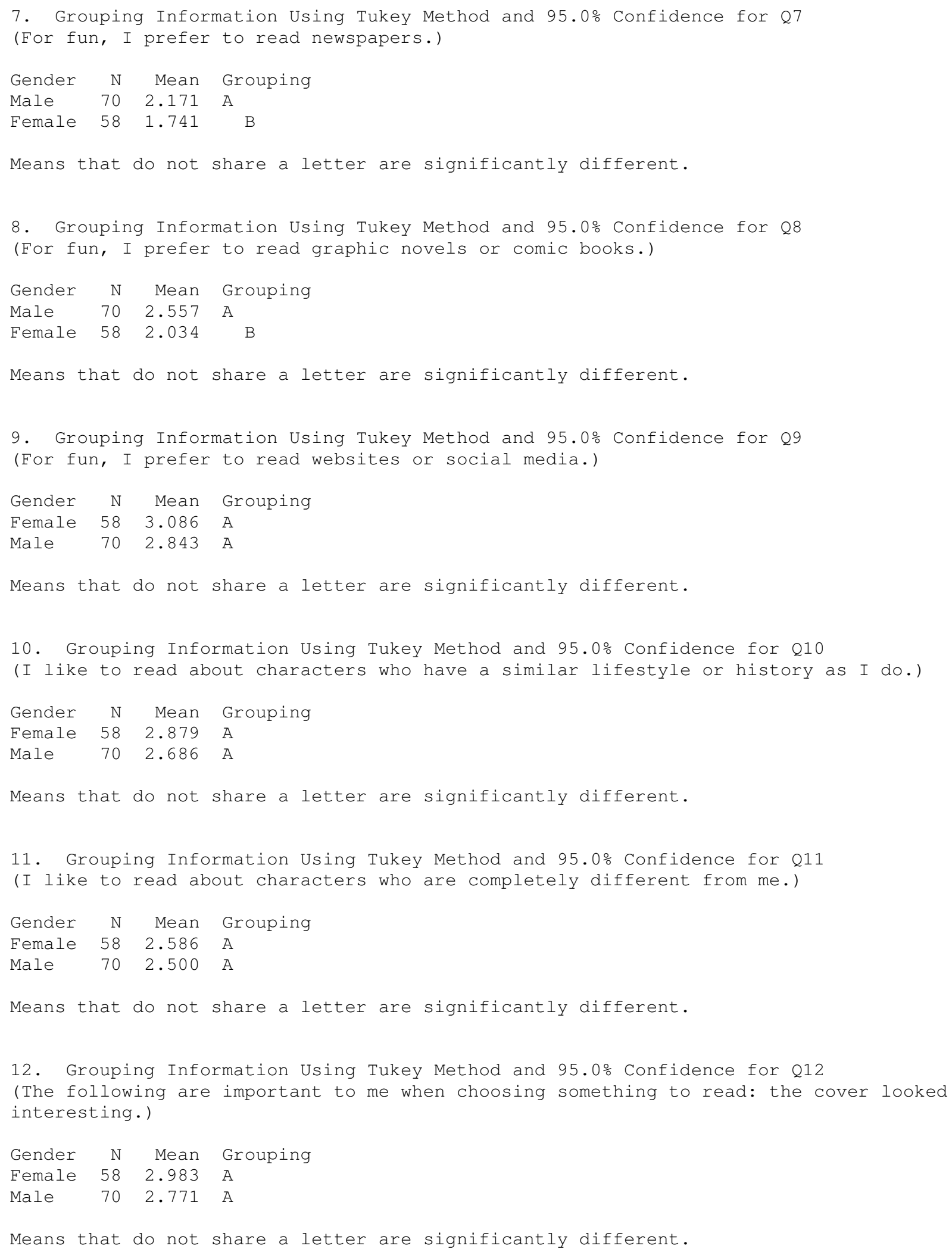


13. Grouping Information Using Tukey Method and 95.0\% Confidence for 213

(The following are important to me when choosing something to read: the summary on the back sounds good.)

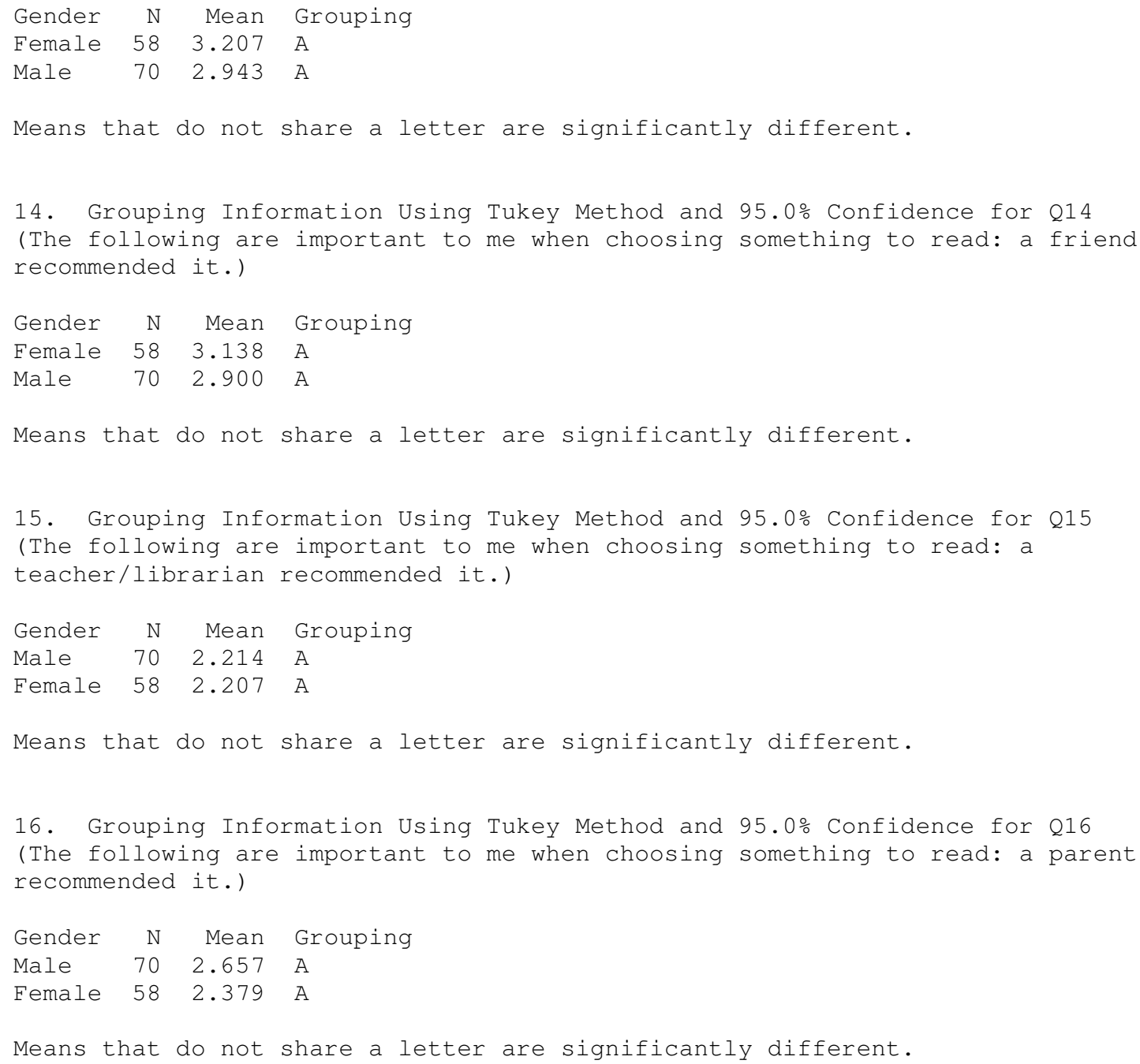


19. Grouping Information Using Tukey Method and 95.0\% Confidence for 019

( I chose the last book I read for fun because the cover looked interesting.)

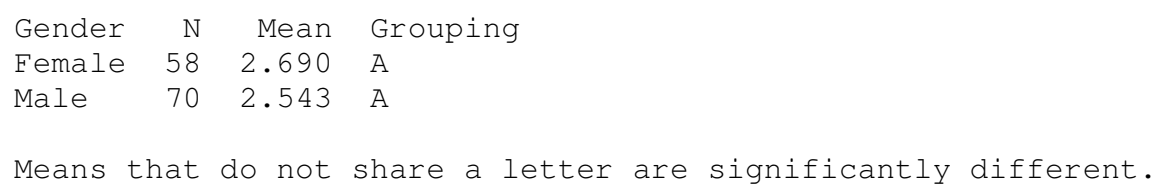


25. Grouping Information Using Tukey Method and 95.0\% Confidence for 225

( I would be MORE likely to read a book if recommended by a(n) parent.)

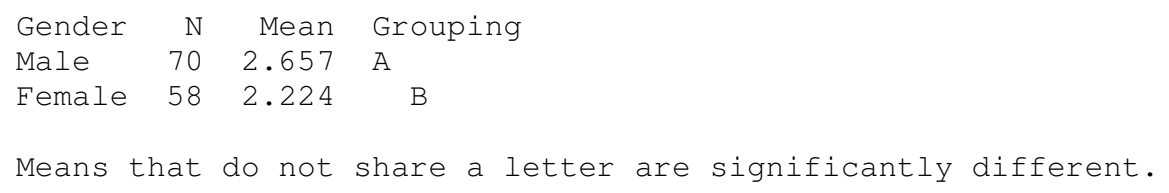

26. Grouping Information Using Tukey Method and 95.0\% Confidence for $Q 26$

( I would be MORE likely to read a book if recommended by a(n) adult friend.)

$\begin{array}{lrrl}\text { Gender } & \text { N } & \text { Mean } & \text { Grouping } \\ \text { Male } & 70 & 2.357 & \text { A } \\ \text { Female } & 58 & 2.293 & \text { A } \\ & \\ \text { Means that do not share a letter are significantly different. }\end{array}$

27. Grouping Information Using Tukey Method and 95.0\% Confidence for 227

( I would be MORE likely to read a book if recommended by a(n) website or social media.)

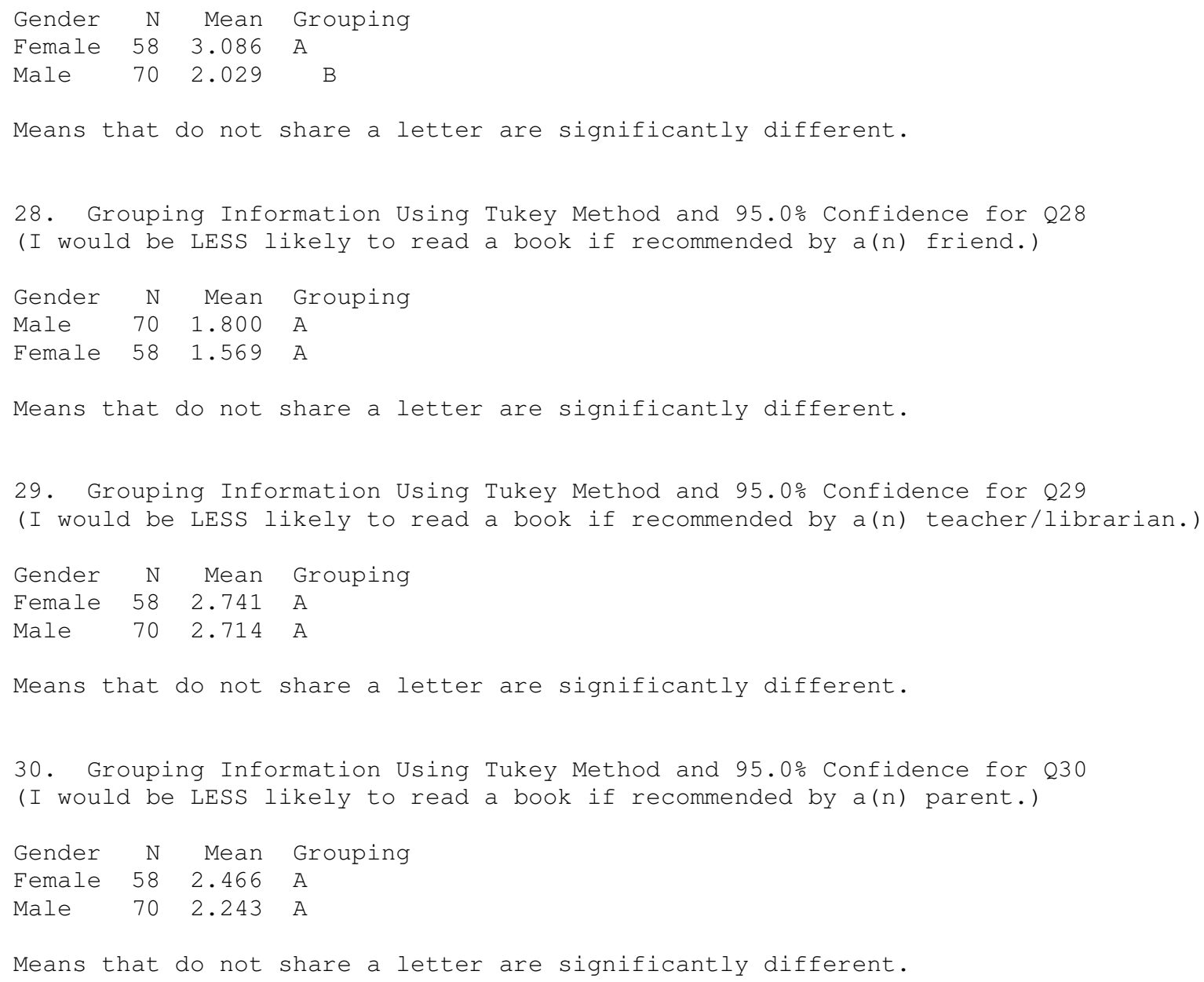


31. Grouping Information Using Tukey Method and 95.0\% Confidence for $Q 31$

( I would be LESS likely to read a book if recommended by a(n) adult friend.)

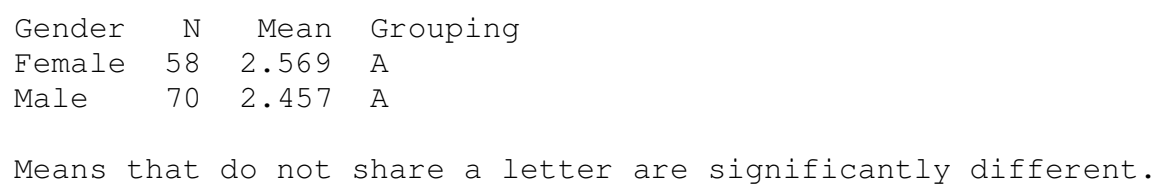


37. Grouping Information Using Tukey Method and 95.0\% Confidence for 237 (I see influential people in my life read in their spare time.)

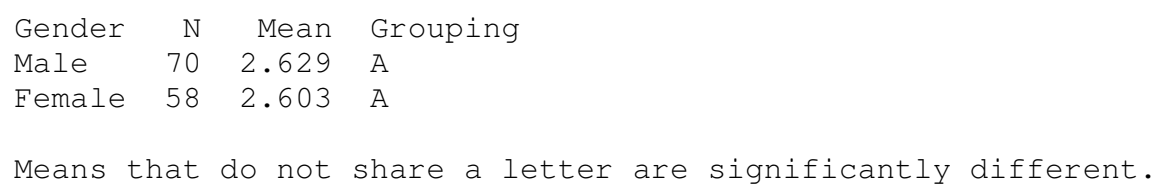




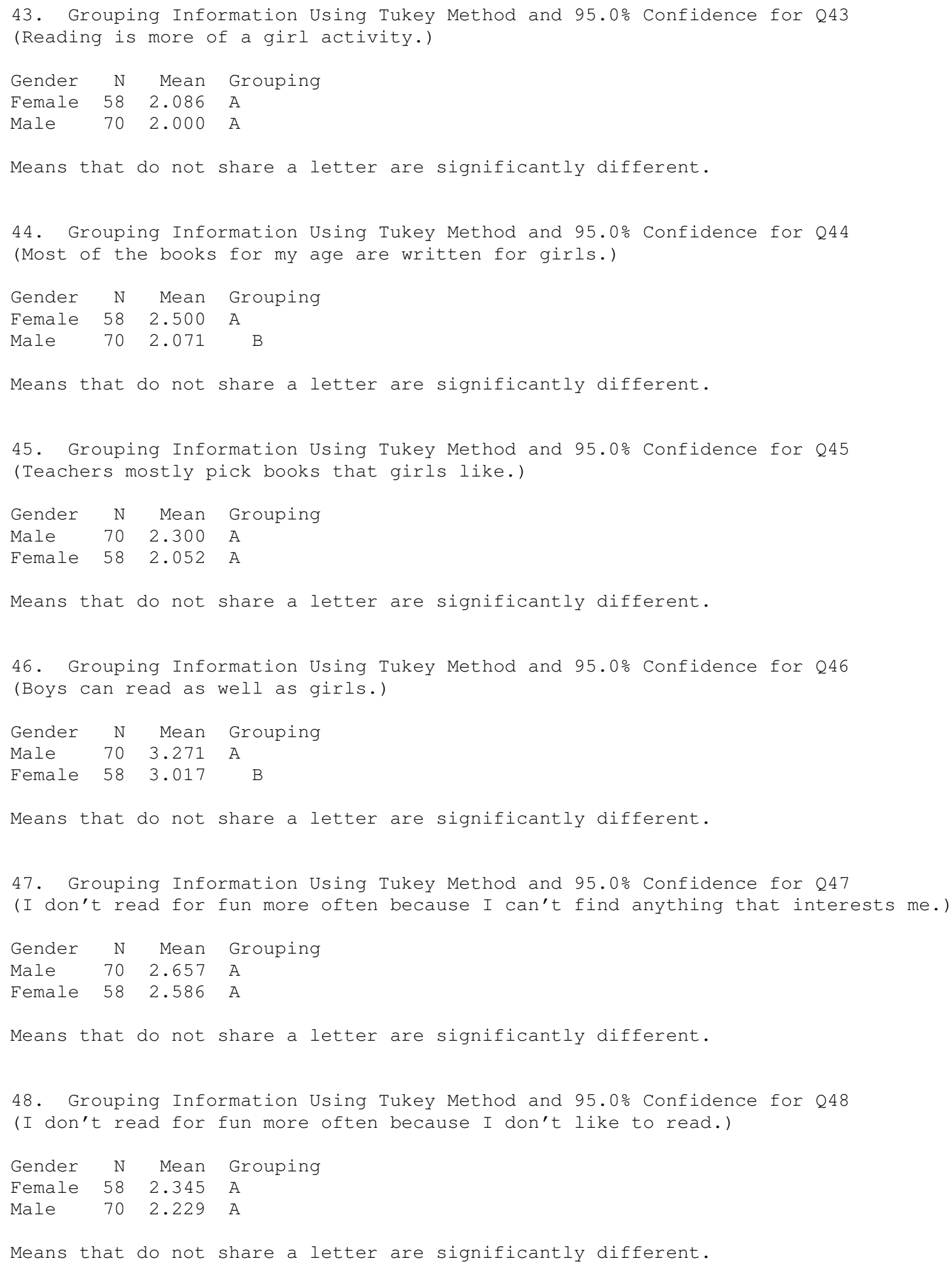




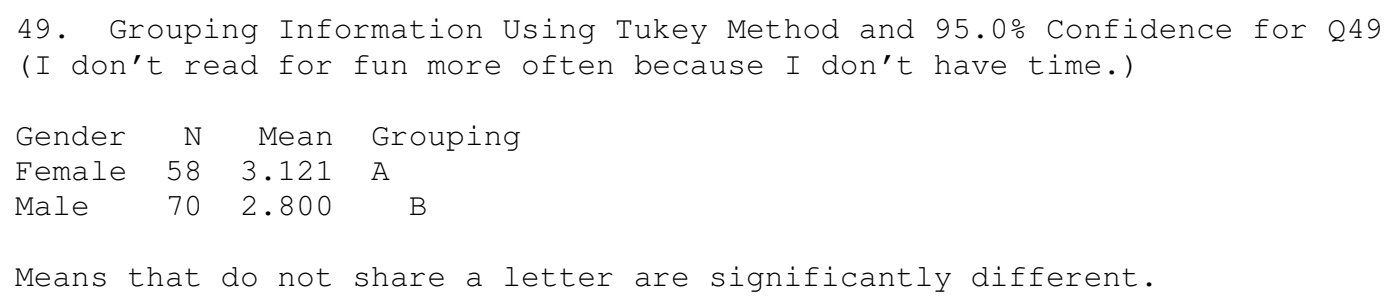


55. Grouping Information Using Tukey Method and 95.0\% Confidence for $Q 55$ (I would read more for fun if I could use audiobooks.)

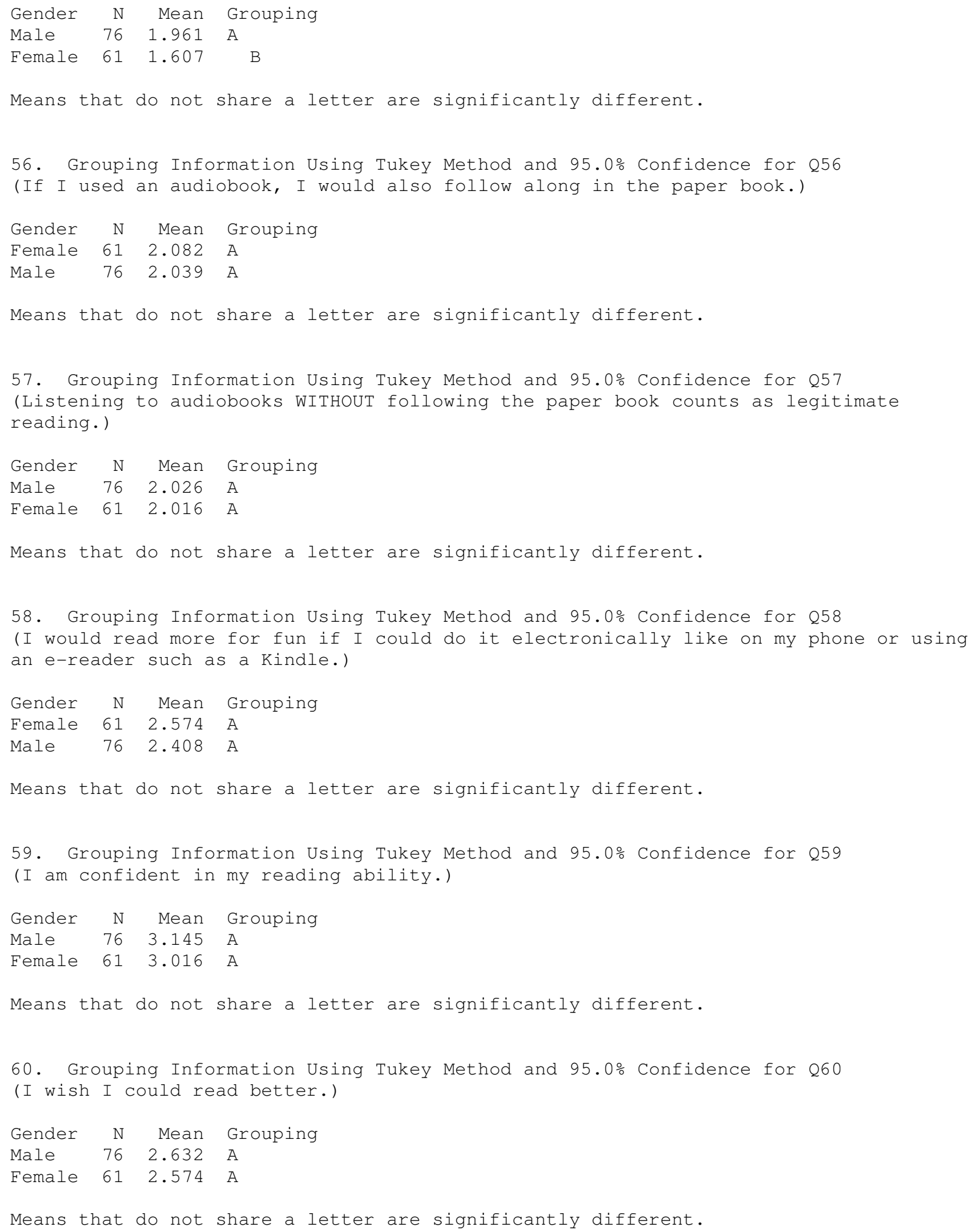


61. Grouping Information Using Tukey Method and 95.0\% Confidence for $Q 61$ (I read LESS for fun than I did two years ago.)

Gender N Mean Grouping

Male $\quad 76 \quad 2.684 \quad$ A

Female $61 \quad 2.639$ A

Means that do not share a letter are significantly different.

62. Grouping Information Using Tukey Method and 95.0\% Confidence for 262 (I read about the SAME amount for fun as I did two years ago.)

Gender N Mean Grouping

Male $76 \quad 2.224 \quad \mathrm{~A}$

Female $61 \quad 2.148$ A

Means that do not share a letter are significantly different.

63. Grouping Information Using Tukey Method and 95.0\% Confidence for 263 (I read MORE for fun than I did two years ago.)

Gender N Mean Grouping

Female $61 \quad 2.230 \quad$ A

Male $\quad 76 \quad 2.026 \quad \mathrm{~A}$

Means that do not share a letter are significantly different. 